$$
\text { WHOI - } 76-36
$$

\title{
A QUASI-LAGRANGIAN STUDY OF MID-OCEAN VARIABILITY USING LONG RANGE SOFAR FLOATS
}

by

\author{
A. D. Voorhis, D. Webb and T. Rossby \\ WOODS HOLE OCEANOGRAPHIC INSTITUTION \\ Woods Hole, Massachusetts 02543
}

Apri1 1976

TECHNICAL REPORT

\begin{abstract}
Prepared for the Office of Naval Research under Contracts N00014-66-C-0241; NR 083-004 (WHOI), N00014-67-A-0097-001 (Yale University) and NSF Grants GX-30220 (WHOI), GX-30416 (Yale University).

Reproduction in whole or in part is permitted for any purpose of the United States Government. In citing this report in a bibliography, the reference given should be to "The Journal of Marine Research, 1975 , Volume 33, No. 3."

Approved for public release; distribution unlimited.
\end{abstract}

Approved for Distribution: Valentine Worthington, Chairman Department of Physical Oceanography 



\title{
A Quasi-Lagrangian study of mid-ocean variability using long range SOFAR floats
}

\author{
by T. Rosslby, ${ }^{1}$ A. D. Voorhis ${ }^{2}$ and D. Webb²
}

\begin{abstract}
Twenty neutrally buoyant SOFAR floats were used in the Mid-Ocean Dynamics Experiment (MODE) to study the structure and variability of the deep ocean currents. The floats were clustered so that the pattern of motions could be resolved (mapping and pattern recognition). A number of float trajectories are shown and the very individual character of their signature is emphasized. Some floats remain nearly stationary for a year whereas others will cover hundreds of kilometers to the south or west in just a few months. Superposition of all trajectories in the spaghetti diagram is shown to reveal considerable organization of the "eddy" field in the MODE area and is thought to be caused by the near presence of the Blake-Bahama Outer Ridge to the west. There is considerable asymmetry to the float dispersal with floats rapidly scattering to the south and west, but not to the north and east even though the r.m.s. velocities are a factor 3 to 6 times greater than the mean drift.

The evolution and dispersal of the float cluster is illustrated in a set of figures in each of which a 12 day segment of all float trajectories is displayed. At times their mobility and relative motion is shown to be associated with onset of sudden swirls and regions of large horizontal shear, features that are not evident from the analysis of individual trajectories.

Cluster averages of the float velocities and kinetic energy, computed weekly and plotted as a function of time, show substantial variability. Much better averages are obtained by limiting the cluster to floats within a geographical region. As the spaghetti diagram indicates and the following paper discusses in more detail there exist substantial geographical variations in the average kinetic energy levels. These may be in some way caused topographically by the close proximity to the continental margin. Whatever the reason they caution us to reexamine the notion that the scale of variation of the second order eddy statistics is large compared to the eddies themselves, at least in the MODE-I area.

Ten floats also contained a system to record the local pressure, temperature and vertical currents. The pressure and temperature yield data concerning low frequency vertical displacements and the vertical current meters measure the internal wave sea state which is shown to be remarkably constant.
\end{abstract}

\section{Introduction}

The observations by J. Swallow and J. Crease during the Aries Expedition (Crease, 1962) of currents in the deep ocean led to the recognition that the dynamics of the

1. Woods Hole Oceanographic Institution, Woods Hole, Massachusetts, 02543, U.S,A. Present address: Graduate School or Oceanographys University of Rhode Island, Kingston, Rhode Island, 02881, U.S.A.

2. Woods Hole Oceanographic Institution, Woods Hole, Massachusetts, 02543, U.S.A. 
ocean were characterized not by steady ocean-wide flows, but by variable and energetic motions having periods of a few months and spatial scales of a few hundred kilometers. These observations stimulated a rapidly growing interest in the structure of the "mesoscale" dynamics and how they may be coupled to the largescale circulation, but progress in understanding these phenomena has been severely hampered. by the lack of instrumentation capable of unattended service for many months at a time. With this need in mind we have, over the last several years, developed a method of observing deep ocean currents by tracking neutrally buoyant floats over great distances from land based SOFAR hydrophones (Rossby and Webb, 1970, 1971). This paper describes the preparations and preliminary results from our participation in the Mid-Ocean Dynamics Experiment (MODE) for which 20 floats were designed and built.

The MODE field program was designed as a cooperative descriptive study in which arrays of different instruments such as moored arrays of current meters and temperature sensors, shipborne density surveys, profilers and bottom mounted instruments would contribute to a synthesis of the evolution of the density and velocity fields during a four month period (March-July, 1973) in a 300 kilometer diameter region (Figure 1) centered at $28^{\circ} \mathrm{N} 69^{\circ} 40^{\prime} \mathrm{W}^{3}{ }^{3}$ The purpose of our participation in MODE with the floats was to measure from their drift the horizontal velocity field at a depth of $1500 \mathrm{~m}$, near the SOFAR channel axis. In particular we hoped:

(i) to map the velocity field accurately in the central region of the MODE area where the density of floats would be fairly high so that this "Lagrangian" description could be compared with the Eulerian current meter maps (accurate maps),

(ii) to map in less detail the peripheral regions with any available floats (pattern recognition), and

(iii) to prepare statistical summaries of the mean and fluctuating fields as well as determine the temporal and spatial scales of coherence of the latter. It should be pointed out that the process of locating the floats was done in "real time" so that we could provide preliminary data on the motion field while the experiment was in progress.

The secondary purpose of the floats was to provide drifting platforms to measure and record vertical water velocity and water temperature. In particular, we hoped to obtain information about the character and stability of the internal wave field and on the magnitude of low frequency vertical currents arising from geostrophic adjustments of the density field.

This paper is intended to provide an overview ${ }^{4}$ of our participation in MODE and an introduction to the information that has been obtained. We begin this report with a brief description of the experiment and its operation. This is followed by a

3. Curiously, there is no official publication of the MODE plan, as adopted by the participating investigators. A summary of the experiment, however, in preparation for publication in Science.

4. For a more detailed account see Voorhis and Webb (1973) and Voorhis and Benoit (1974). 


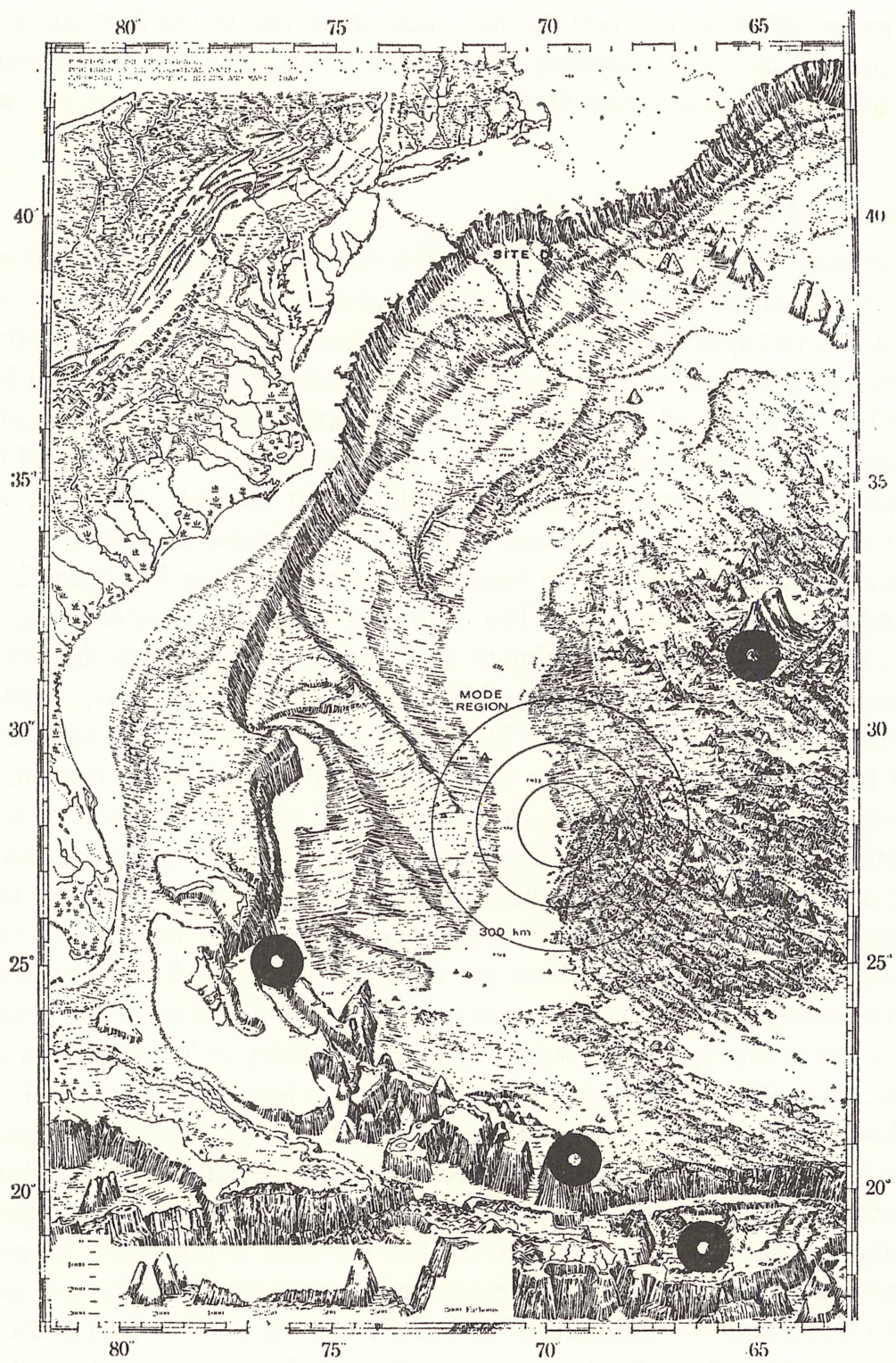

Figure 1. Physiographic diagram of the western North Atlantic. The MODE-I region, which is indicated by three concentric rings of $100,200,300 \mathrm{~km}$ radius, straddles the rough bottom to the east, the Hatteras Abyssal Plain to the west and further to the west the Blake-Bahama Outer Ridge. The float monitoring sites are indicated by the rings.

presentation and discussion of the trajectory data including a statistical summary of the average velocity and kinetic energy fields. The environmental data that was collected by the floats is briefly reviewed the last section. 
In the paper following this one the statistical properties of the fluctuating velocity field is examined in detail. Mapping experiments of the velocity field, intercomparisons of the Lagrangian/Eulerian field measurements and other studies will be forthcoming.

\section{The floats and shore listening system}

a. Float details. Twenty numbered floats of a new design were proposed and ultimately constructed for MODE. Each float was equipped with two acoustic signaling systems: a low frequency system for long-range shore location and a high frequency subsystem for shipboard location and command recovery. Incorporated in the latter was an AMF receiver and decoder, and a weight jettison assembly. In addition, ten of the floats contained a subsystem for the measurement and recording of environmental variables; temperature, pressure, and vertical current. All floats were designed to operate at 1500 meters, and to have an endurance of 1 year.

The float structure, shown in its operating upright position in Figure 2, consists of 3 cylinders of aluminium alloy. The central cylinder is 5.2 meters long, $30.5 \mathrm{~cm}$ diameter, with hemispherical aluminium and closures and contains the battery and electronic equipment. The two short cylinders are the low frequency sound transducers which operate freely flooded. The upper end is open and the acoustic driver, a bender plate, is fitted to the lower end. The transducer tubes are mounted on the main housing with 4 heavy stainless steel studs. A $7.3 \mathrm{~kg}$ cylinder of lead is connected to the lower end through an electrically controlled release mechanism, and is jettisoned for float recovery on command from the surface. Not visible in the figure is the small high frequency ceramic transducer connected to the bottom end.

The details of the signaling systems are shown in Table 1. All signals were derived from a temperature compensated quartz oscillator with an offset of not greater than $1 \mathrm{ppm}$. Electrical energy was furnished by a single battery of $73 \mathrm{~kg}, 30$ volt nominal, $5 \mathrm{KW}$ hrs. Over $90 \%$ of the energy was used in the low frequency signal.

The three environmental variables were sampled every $256 \mathrm{sec}$. and recorded on magnetic tape using a Sea Data digital recorder with specially developed low power sensor circuits. Water pressure was also telemetered to the sea surface in digital code via the short range relocation system so that the float depth could be monitored by a nearby ship. Vertical water currents were sensed by the technique developed by Webb (Webb and Worthington (1968)) and exploited by Voorhis (1968). Because the compressibility of the float is less than that of the sea water, vertical currents generate relative vertical flow past the drifting float. This flow acts on an array of tilted vanes mounted axially around the main cylinder at its midlength, forcing the entire to rotate about its vertical axis ( $1 \mathrm{rev}$. per $5.8 \mathrm{~m}$ of vertical water displacement). The resulting rotation is sensed relative to an internal magnetic compass. The vanes (not attached to the float in Figure 2) consist of four plates of polypropylene $30 \times 50$ $\mathrm{cm}$ mounted at $45^{\circ}$ to the float axis. The accuracy, resolution, and estimated drift of the environmental measurements are summarized in Table 2. 


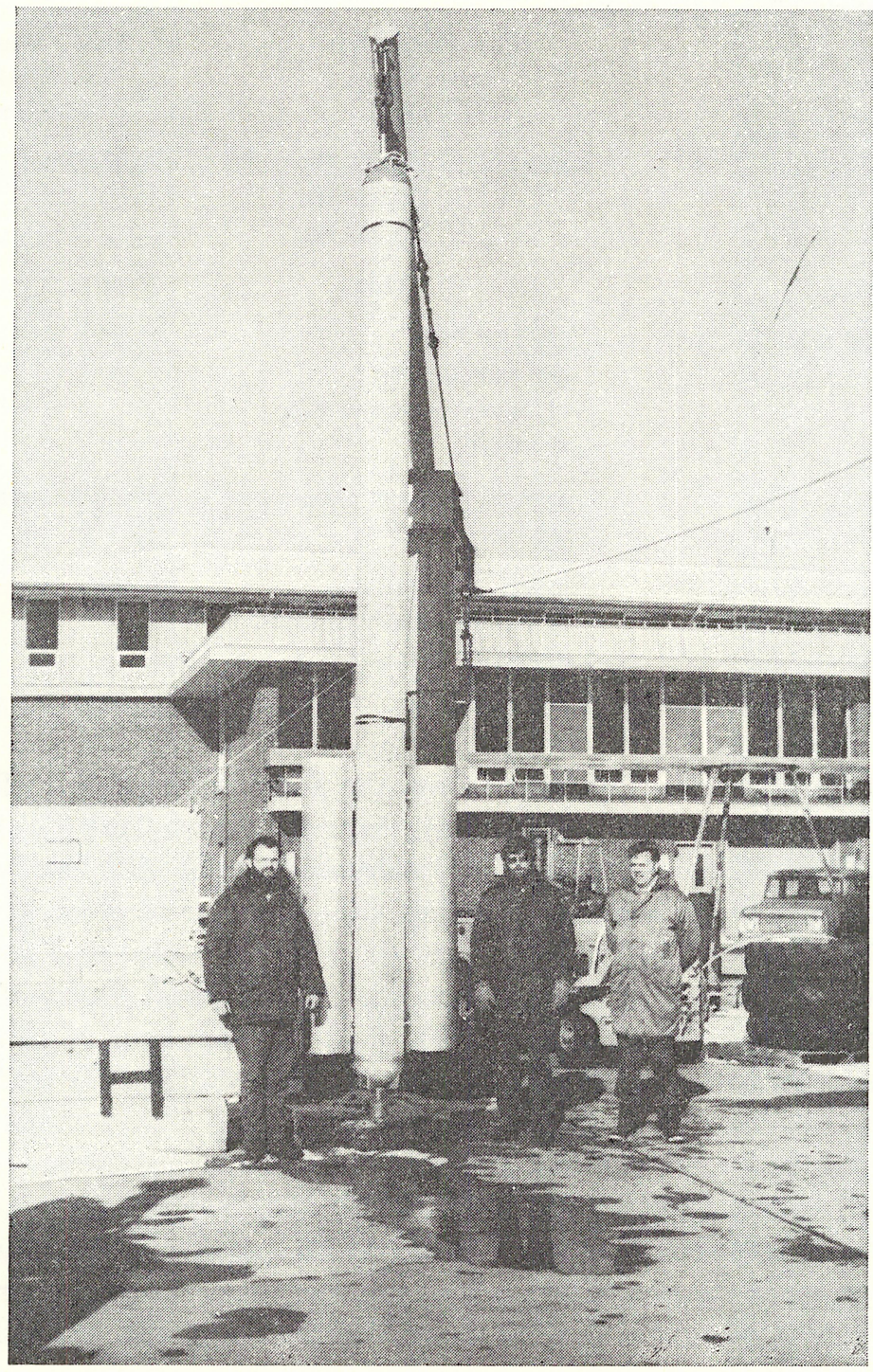

Figure 2. The complete float assembly ready for ballasting. The two shorter tubes are the low frequency acoustic resonators.

The completed float weighs $430 \mathrm{~kg}$ and has a bulk compressibility of $1.63 \times 10^{-6}$ per meter increase in depth and a bulk thermal expansion coefficient of approximately $76 \times 10^{-6}$ per ${ }^{\circ} \mathrm{C}$. The upward restoring force at $1500 \mathrm{~m}$ in the MODE area was 1.15 gms per meter depth increase. Float ballasting was done by weighing the instruments in harbor water off the W.H.O.I. dock. Surges due to wave action were minimized by suspending the floats in a highway culvert standing on end on the harbor bottom. 
Table 1. Float signaling characteristics.

\begin{tabular}{|c|c|c|c|}
\hline \multirow[b]{2}{*}{ Carrier frequency ......... } & \multicolumn{2}{|c|}{$\begin{array}{l}\text { Low Frequency } \\
\text { Long Range } \\
\text { Location }\end{array}$} & \multirow{2}{*}{$\begin{array}{l}\text { High Frequency } \\
\text { Short Range } \\
\text { Location } \\
10,000 \mathrm{~Hz}\end{array}$} \\
\hline & one of 3 & $\begin{array}{l}267.130 \mathrm{~Hz} \\
270.066 \mathrm{~Hz} \\
273.067 \mathrm{~Hz}\end{array}$ & \\
\hline Pulse duration ........... & & $5 / 3 \mathrm{sec}$ & 10 msec. \\
\hline Pulse repetition rate...... & \multicolumn{2}{|c|}{$\begin{array}{l}1437 \text { to } 1443 \\
\text { transmission/day* } \\
(1 \text { transmission per min } \\
\text { nominal) }\end{array}$} & $4 \mathrm{sec}$ \\
\hline Sound power............. & \multicolumn{2}{|c|}{$\begin{array}{l}\text { approx. } 77 \mathrm{db} \text { re } 1 \mu \mathrm{bar} \\
\text { (@) } 1 \mathrm{~m}\end{array}$} & $\begin{array}{l}80 \mathrm{db} \text { re } 1 \mu \mathrm{bar} \\
@ 1 \mathrm{~m}\end{array}$ \\
\hline Identification . ............ & \multicolumn{2}{|c|}{$\begin{array}{l}3 \text { carrier frequencies } \\
\& 7 \text { pulse repetition rates, } \\
\text { giving } 21 \text { channels }\end{array}$} & None \\
\hline
\end{tabular}

b. Shore listening system. The signals from the floats are received at four widely spaced SOFAR hydrophones at Bermuda, Bahama, Grand Turk (Walden et al., 1973), and Puerto Rico at ranges of approximately 500 to $1000 \mathrm{~km}$. After amplification, filtering and the addition of timing, the signals are recorded in digital and graphical form. The digital magnetic tapes are routinely mailed to Yale University for analysis. The graphical records provide an immediate visual display of the overall performance and signal arrival time of any float and also provide redundancy in case of undetected failure of the digital system. During MODE daily readings of the graphical records were made and the data telephoned to Yale for real time location of the floats. A more detailed description of the data acquisition and analysis was reported earlier (Rossby and Webb, 1970). The navigational resolution for the trajectory data reported here is typically \pm 500 meters and the accuracy about 2 to $3 \mathrm{~km}$. A good fraction of this error, however, is due to our assumption of a "universal" speed of sound of 1492 meters/sec. througout the Bermuda triangle. (Figure 1).

Table 2. Quality of float environmental data sensor and recording system.

\begin{tabular}{|c|c|c|c|}
\hline & $\begin{array}{l}\text { R.M.S. } \\
\text { Accuracy }\end{array}$ & $\begin{array}{c}\text { Least Count } \\
\text { Digital Resolution }\end{array}$ & Mean Drift \\
\hline Water pressure ...... & $5 \mathrm{dbar}$ & $.14 \mathrm{dbar}$ & approx. $4 \mathrm{dbar} / \mathrm{mo}$. \\
\hline Water temperature... & $.044^{\circ} \mathrm{C}$ & $.0035^{\circ} \mathrm{C}$ & less than $.001^{\circ} \mathrm{C} / \mathrm{mo}$. \\
\hline $\begin{array}{l}\text { Relative vertical } \\
\text { water displacement... }\end{array}$ & $5 \%$ & $9.1 \mathrm{~cm}$ & \\
\hline
\end{tabular}




\section{Description of field experiments}

a. Pre-MODE trials. Two field trials were carried out prior to MODE. The first was made from the W.H.O.I. ship R.V. CHAIN at the end of September 1972. Two prototype non-instrumented floats were launched somewhat to the south of the MODE area to be tracked from the shore stations and finally recovered during the second trial scheduled for November 1972. Both floats were readily tracked over this period and thus the greatest uncertainty of the float design was eliminated; that is, whether the new low frequency float sound projectors would deliver enough acoustic energy at a depth of $1500 \mathrm{~m}$ to be detected by the shore tracking stations over a distance of as much as $1000 \mathrm{~km}$.

The second and last trial occurred in mid-November 1972 from the R.V. CHAIN and was planned to be a dress rehersal for MODE. In particular, the shipboard tracking system and a new technique for float launch and recovery were to be tested. Upon arrival in the MODE area, both the floats which has been launched in September were quickly located using shore and ship tracking information. One was recovered but the other refused to surface on a command release and later on its timed release (it was tracked for another month and ultimately went silent towards the end of December 1972). Early in the trial three new instrumented floats were launched to drift at $1500 \mathrm{~m}$ for a period of three to four days to test their sensing and data recording systems. Two of these successfully passed this test and were recovered with data. The other was never recovered. It showed symptoms of electronic malfunction soon after launch and refused to surface on either command or timed release. After a drift of less than two weeks it went silent, due probably to unbounding of the low frequency projector seals. This was unrecognized at the time but caused problems later in MODE. Before leaving the area the two floats were relaunched to be tracked over the winter and recovered at the beginning of MODE.

b. MODE and post MODE. All shipboard SOFAR float work during MODE was carried out from the NOAA ship RESEARCHER during five legs at sea, from 8 March through $13 \mathrm{July,}$ 1973. The available ship time was shared with the programs for density measurement, inverted echo sounders, and deep sea tides. The experiment was started with eighteen floats, sixteen on board ship when it arrived in the area plus two to be recovered from the November trials.

On the first leg (8 through $29 \mathrm{March}$ ) eight non-instrumented floats were launched. Seven of these were equally spaced on a circle of $120 \mathrm{~km}$ radius from MODE center for extended pattern recognition and the eight at the center. All floats were detected immediately at the shore stations and tracking commenced. Of the two floats from the November trials one was recovered and the other failed to surface either on command or timed release. However, tracking of the latter continued throughout MODE (and into August for a drift of over eight months). At the end of the first leg one float has been lost and eight were being tracked successfully.

On the second leg ( 5 through 26 April) the float strategy was to launch all remaining 
floats (instrumented) on or near a circle of radius $50 \mathrm{~km}$ from MODE center for accurate current mapping and for intercomparison with moored current meters which by then were in place. This was accomplished in the main. However, it became apparent at the shore tracking stations that too many floats were failing after a drift of less than two weeks. Most of these floats were located by their high frequency, short range, pinger and were recovered. Examination showed that failure was due to unbonding of their low frequency projector seals. Fortunately, each float had two projectors and in most cases only one had unbonded, shorting out the other. As a temporary measure it was decided to electrically isolate the unbonded projector, and relaunch some of these floats to be tracked using the remaining good projector (which might fail at any time). At the same time a new projector seal was designed, to be completed at Woods Hole during the third leg, and to be installed at sea on all floats as soon as possible during the last two legs. This plan proved successful. Twelve floats were being tracked at the end of the second leg.

During the third leg (1 through 23 May) three failed floats were recovered for projector repairs and one float with a single working projector was relaunched.

Originally, the strategy for the fourth leg (29 May through 20 June) was to recover those floats which had drifted out of the MODE area and relaunch them within the $50 \mathrm{~km}$ radius inner zone for a second intercomparison with the moored current meters, before the latter were recovered at the end of the experiment. This was readily accomplished because float dispersion had been less than anticipated. Before relaunch all floats had their low frequency projectors resealed according to the new design. Finally, most floats had their batteries recharged and were modified for an indefinite post-MODE drift before final relaunch. Their recovery and sensing systems were removed and their signaling rate reduced to one-third to lengthen their battery life.

On the fifth and last leg (25 June through 13 July) all remaining recoverable floats were retrieved and modified as on the previous leg and then relaunched for indefinite drift. At the end of MODE fourteen floats were being tracked from the shore stations. Of these, eleven had been completely modified. Of the original twenty, only six floats had been lost.

Drift depth during the four-month experiment could be determined only for the ten instrumented floats. Their pressure sensors showed a mean depth of $1525 \pm 24$ meters after launch. Thereafter, they sank an additional $15 \mathrm{~m}$ within the first $24 \mathrm{hrs}$ and then throughout their drift sank gradually at the mean rate of $0.85 \mathrm{~m} /$ day. This slow sinking, we believe, was caused by contraction of the main cylinder due to compressional creep. It is readily estimated that the average float during MODE, assuming that all behaved similarly, drifted at a mean depth of 1555 meters.

Within a few months after MODE-I the remaining unrepaired floats failed. Figure 12 shows the number of floats being tracked as a function of time. It is noteworthy that two years after the end of MODE-I five floats are still being tracked on a routine basis. 


\section{Float trajectories}

a. Pre-MODE. The pre-MODE trials, besides being essential technical trials, were designed to provide information about the vertical and horizontal shear on geostrophic time scales. Although this information was becoming available in Eulerian form from the arrays of moored current meters that were set in MODE-O, it was evident that Lagrangian measurements of vertical and horizontal shear were necessary first steps in the design of a good Lagrangian experiment.

1. Figure 3 shows the trajectories of two floats launched with a vertical separation of 310 meters (1290 and

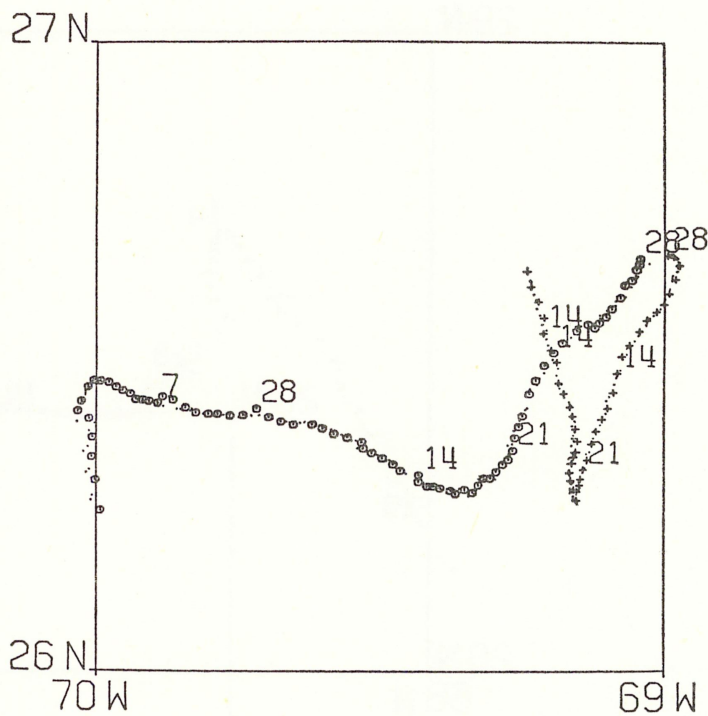

Figure 3. Trajectories of float \#11 (๑) at 1290 meters depth $(9 / 28 / 72-12 / 25 / 72$, lost $)$ and \# $13(+$; at 1600 meters depth $(9 / 28 / 72-11 / 18 / 72$, recovered). 1600 meters, respectively). Their initial separation was about $5 \mathrm{~km}$, which after 4 weeks had grown to $16 \mathrm{~km}$, corresponding to a relative velocity of $0.5 \mathrm{~cm} / \mathrm{sec}$. This is rather small and suggested to us that if we could keep all of the floats at the same level ( \pm 50 meters, say) we would be subject to very little "aliasing" by low frequency vertical shear. It is true that the speeds were only about $2 \mathrm{~cm} / \mathrm{sec}$ during this period, but even if the shear were proportionally larger at the more typical velocity of $5 \mathrm{~cm} / \mathrm{sec}$, it would still be numerically small at these depths. The results of this study we felt, were very encouraging.

As the horizontal separation between the floats increases it is evident that horizontal shear will become the dominant factor in the subsequent relative motion. This is a likely cause for the change in relative motion starting around October 25, 1972. Although the speeds were still small, the deep float turned north while the shallow one turned westward.

2. The second pre-MODE trial was designed to look at the horizontal field at a single depth, for which 3 floats are a necessary minimum to determine the velocity and its first space derivatives. To optimize this the three floats were launched in an equilateral triangle $\sim 32 \mathrm{~km}$ on the side. It was unfortunate that one of these failed after only 1 week. In spite of this loss, the movements of the remaining two floats (Figure 4) was unexpected. On the basis of a growing body of data it was expected that they would show a westward drift. Instead they moved eastward, albeit slowly. Perhaps more remarkable is that one of the floats (\# 4), which continued until the end of July 1973, always stayed within a $100 \mathrm{~km}$ box, i.e., it showed no measurable net drift. 


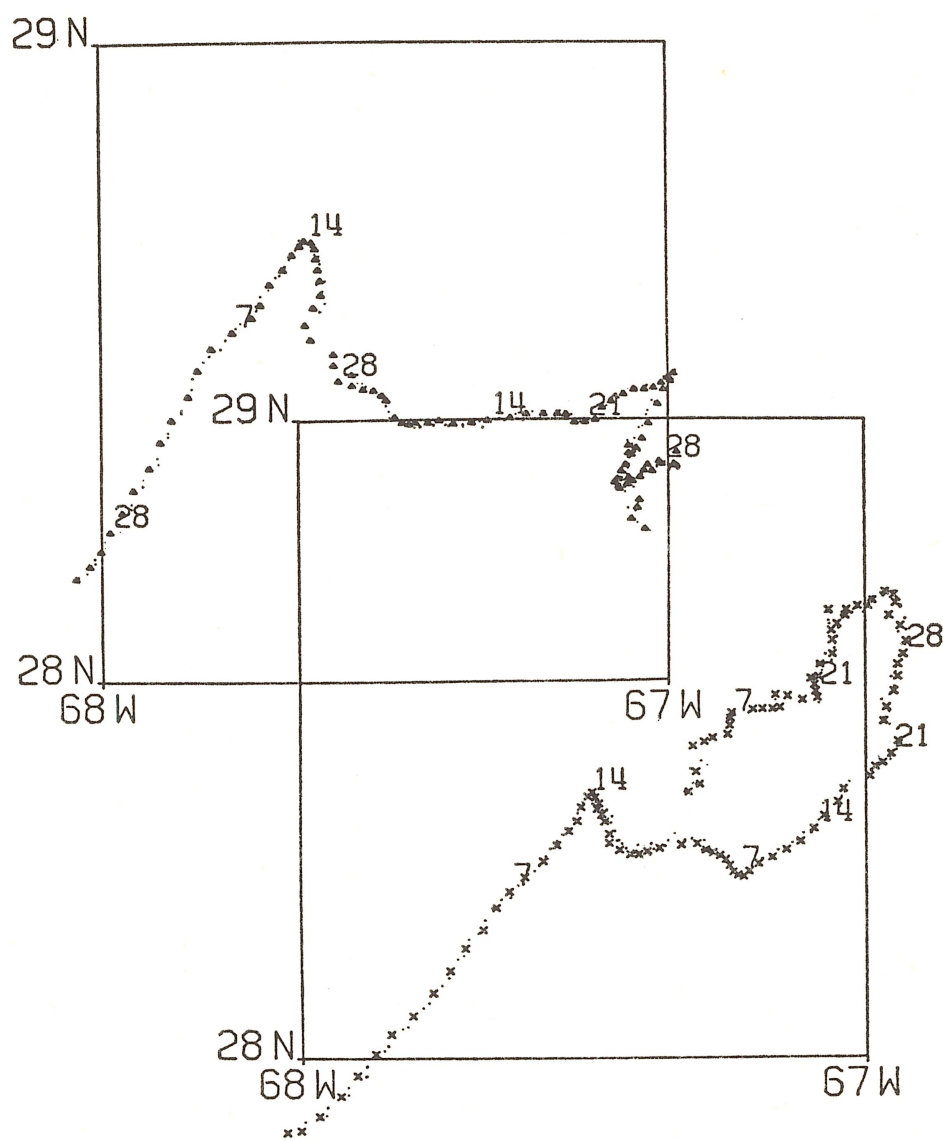

Figure 4. Trajectories of float \# 4 ( $x)(11 / 24 / 72-2 / 20 / 73)$ and float \# 12 (A) (11/24/72-2/20/73).

Contrary to the previous vertical shear experiment, the separation between the two changed very little, although they did rotate about each other. The visual similarity of the two trajectories gave the impression that the horizontal scale of the velocity field was not significantly different from previous studies in spite of the rough bottom topography in this region. On the other hand, the low trajectory speeds of both of these floats were at variance with what earlier experiments with floats (Crease, 1962; Rossby and Webb, 1971) had led us to expect.

c. MODE and post MODE. In Figures 5 through 9 we show a representative set o1 trajectories obtained during and after the main field study. Information about the individual trajectories is provided in the figure captions. We should like to emphasize the individual character of each of these. Some floats show next to no net displacement in the horizontal whereas others will traverse great distances, sometimes quickly. 
For example float \# 17 in Figure 5 moves back and forth in a $1^{\circ}$ square box for about 15 months before it took off to the northwest. During this time it shows no net displacement yet it maintains average trajectory speeds. This situation is also true of float \# 4, mentioned earlier. Quite the opposite was the behavior shown by float \#1 which at first moved boldly to the west and then veered to the south, Figure 6; and float \# 20 in Figure 7, which in six months almost reached the British West Indies corresponding to an average southward velocity of $3 \mathrm{~cm} / \mathrm{sec}$. Another float, Figure 8, upon reaching the eastern slope of the Blake-Bahama outer Ridge underwent a striking set of oscillations, which immediately disappeared as soon as the float returned to the Hatteras Abyssal Plain. Some float tracks suggest nearly periodic motion, Figures 5 and 9. Despite the dissimilarity of individual trajectories, they tend to be rather smooth on a day by day basis with only gentle accelerations or changes in direction.

When all of the trajectories are superimposed without regard to time, we obtain the "spaghetti" chart shown in Figure 10. What we see in cumulative form is the manner and way the floats move about in different geographical regions. Several striking features stand out immediately.

1) The trajectory field reveals significant organization. At $28^{\circ} \mathrm{N}$ there is predominantly zonal eddy motion whereas to the north as

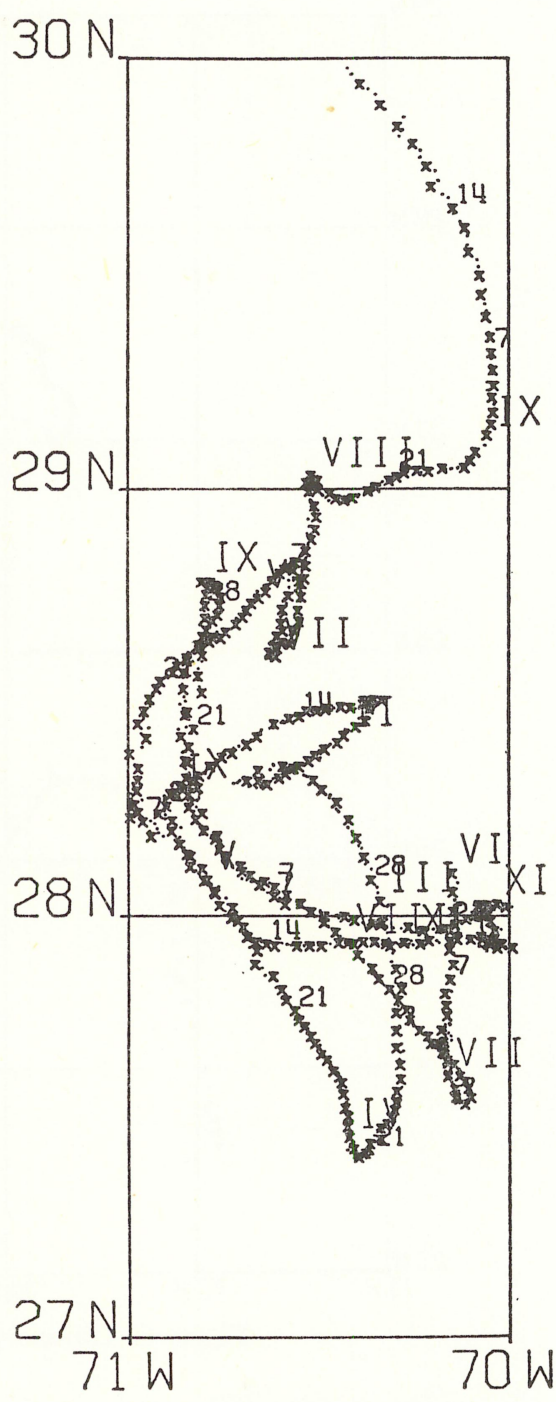

Figure 5. Trajectory of float \# 17 (5/31/739/20/74). well as to the south the trajectories have a more north-south orientation. An obvious candidate for the "steering" of the fluctuating currents at these latitudes would be the Blake-Bahama Outer Ridge to the west of the MODE area (Figure 1). We do not see as much organization further south.

2) The dispersion of the cluster appears to be more vigorous in the $N / S$ than in the E/W direction. This may be due to the N/S orientation of the Hatteras Abyssal Plain or the near presence of the continental slope to the west. 


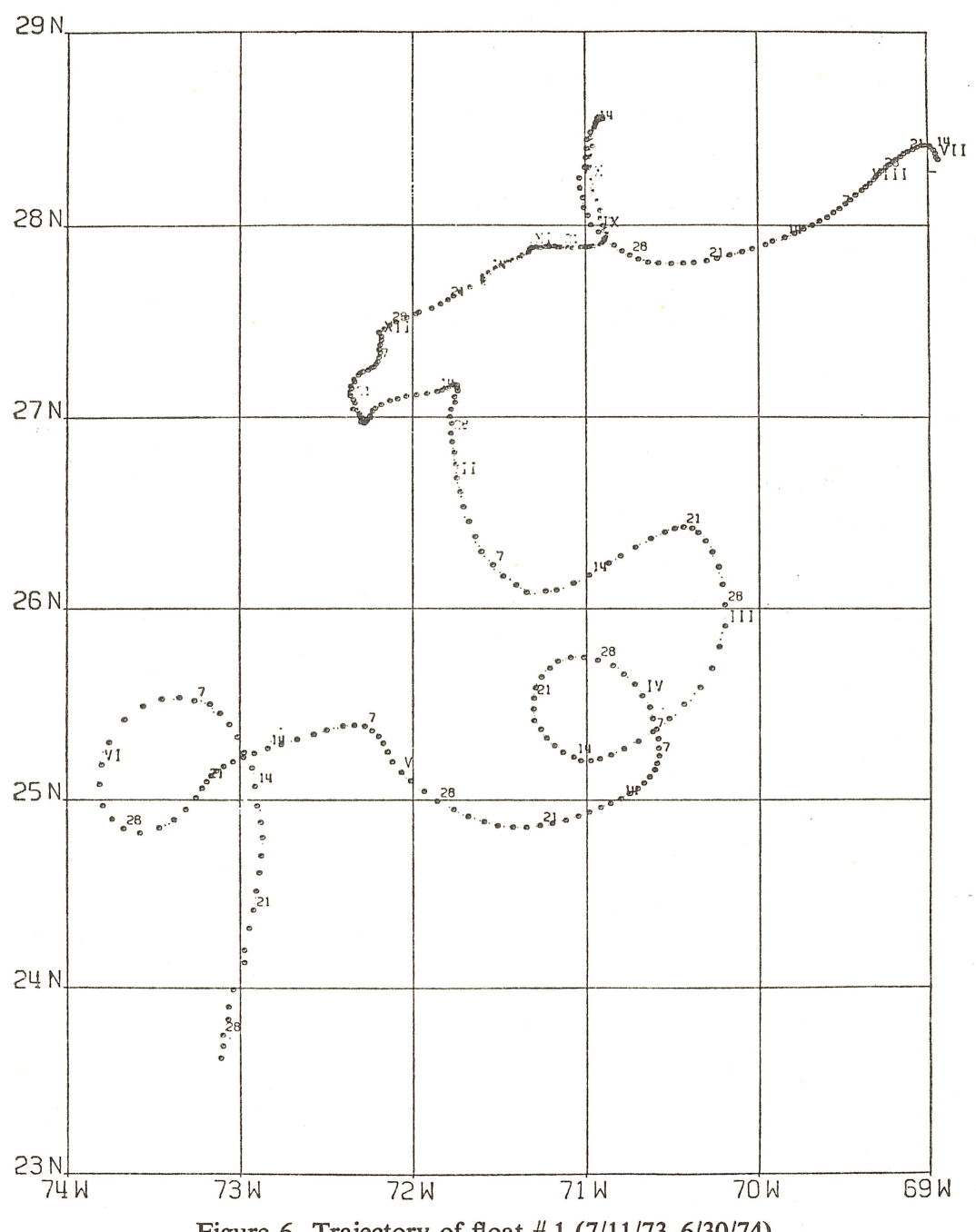

Figure 6. Trajectory of float \# 1 (7/11/73-6/30/74).

3) Floats do not disperse to the north or east. This is curious in view of the fact that the average trajectory speeds are a factor 3 to 6 times greater than the drift of the cluster, which is a little less than $1 \mathrm{~cm} / \mathrm{sec}$ to the west.

4) The speeds of the floats (the dots along the track are $1 /$ day) are obviously less in the eastern portion than in the west. This may be because of the much greater bottom roughness in the eastern region or it may be evidence of west/east decay of reflected planetary waves off the continental margin to the west (Phillips, 1966; Rossby and Webb, 1971).

In summary, the "spaghetti" chart suggests considerable geographical variation in the structure of the fluctuating field. At the latitude of the MODE-I experiment 
$\left(28^{\circ} \mathrm{N}\right)$ there is an evident $\mathrm{W} / \mathrm{E}$ gradient in the trajectory speeds. Similarly to the north but most especially to the south we note much larger speeds. That there should exist such local geographical variations in the kinetic energy levels was not expected by any of us.

d. The space-time evolution of the cluster. Neither the individual trajectories nor the spaghetti diagram can justly portray the remarkable mobility and relative motion of the floats. In order to give the reader a feeling for this we have prepared a set of charts, Figure 11a-g, 12 days apart, showing the temporal evolution of the cluster. The figures are excerpts from a film Diane Dow and Peter Rhines prepared from the float data at the National Center for Atmospheric Research, Boulder, Colorado. The dates indicate the "present" positions of the floats and their motion is shown as a 12 day sliding trajectory with the 6 most recent days indicated by a solid line and the 6 preceeding days by a dotted line. If the float is moving slowly, the dots are not apparent and the direction of motion must be inferred from the preceeding or subsequent figure.

The bottom topography is shown schematically by the solid ( 5400 metsrs) and dashed (5000 meters) lines. In the north-west corner the 4000 meter isobath on the Blake Bahama Ridge is indicated.

The floats used by Dr. John Swallow (IOS) in the "minimode" experiment are visible in April 1973 near $28^{\circ} \mathrm{N}, 70^{\circ} \mathrm{W}$ and in May 1973 near $28^{\circ} \mathrm{N}, 68^{\circ}-69^{\circ} \mathrm{W}$. They were used during MODE-I to study vertical and horizontal shear over smaller scales, first over a flat bottom (April) and then over a rough bottom (May). Unfortunately the scale we have chosen for these

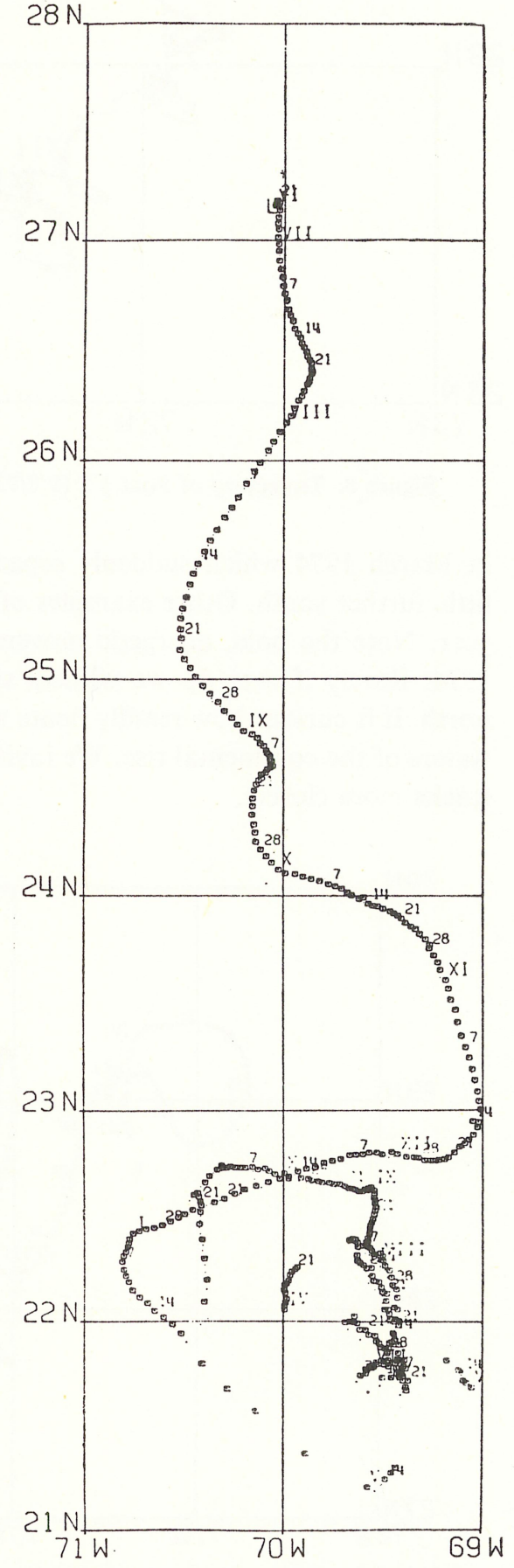

Figure 7. Trajectory of float \# $20(6 / 18) 73$ 10/27/74). 


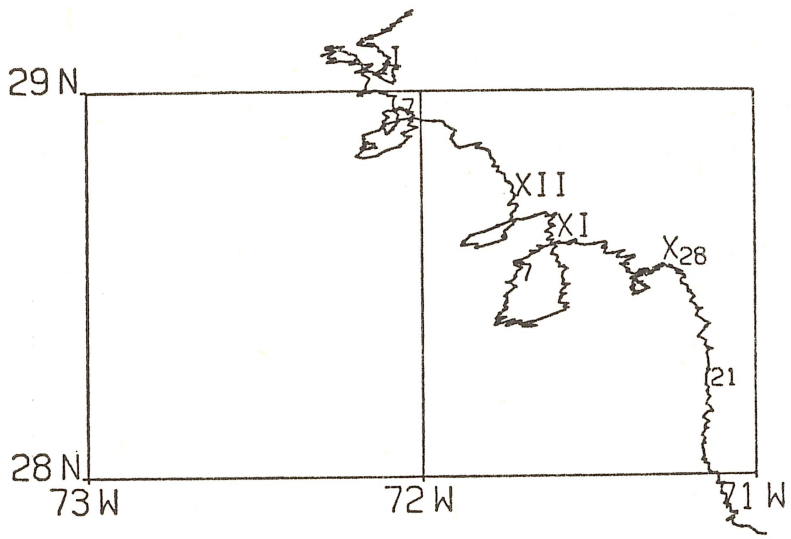

Figure" 8 . Trajectory of float \# 2 (9/8/73-1/12/74).

figures is such that their movements are difficult to resolve.

Perhaps the most visible event is the swirl that was quickly established (and just as quickly disappeared) in August 1973. The relative vorticity is approximately $3 \%$ of the planetary vorticity. A similar but less intense event is also evident in April 1973. Relative motion of neighboring floats is sometimes incredible such as the two floats

in March 1974 which suddenly separate. A similar event occurs a month earlier a little further south. Other examples of strong horizontal shear occur throughout the year. Note the bold, energetic movements of the southern group of floats in early 1974. Rarely if ever do we witness similar velocities in the MODE-I area further north. It is curious how readily floats will reach to the south, but not into the shallow waters of the continental rise. We invite the reader to study this "time series" of float tracks more closely.

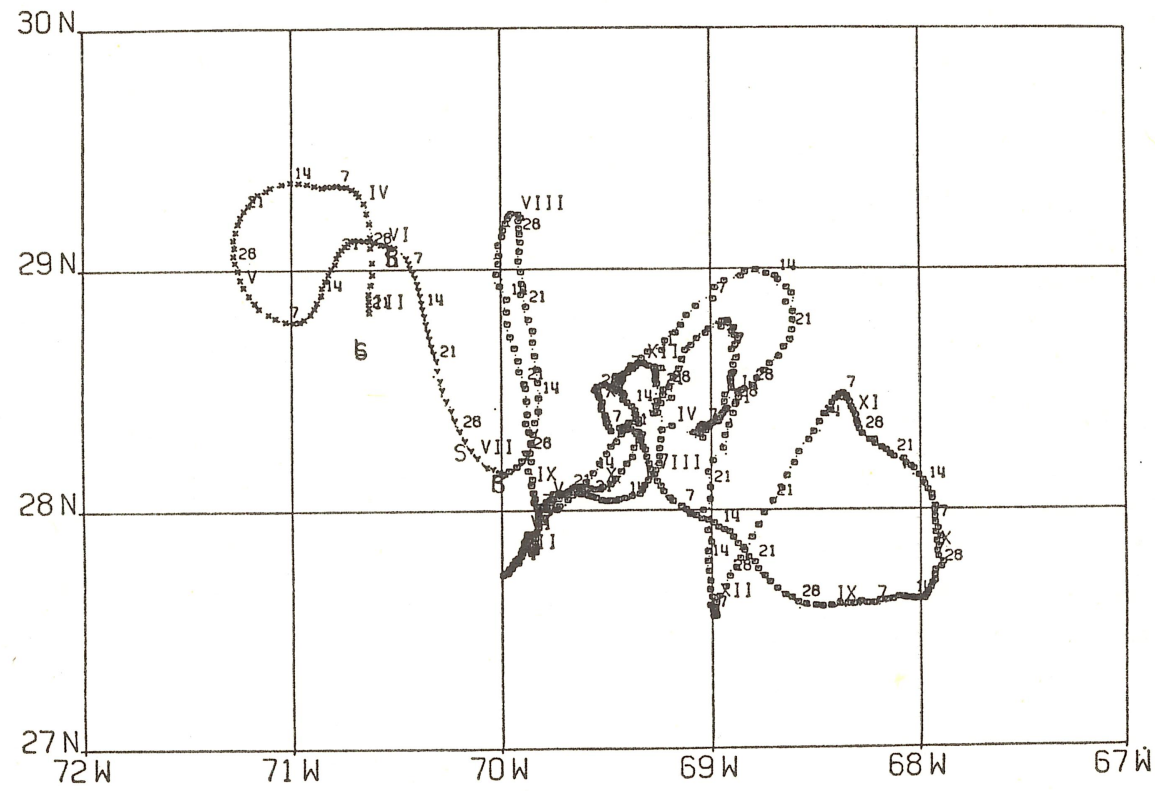

Figure 9. Composite trajectory of several consecutive floats (i.e., a float is launched as another is recovered) $(3 / 21 / 73-12 / 31 / 74)$. 


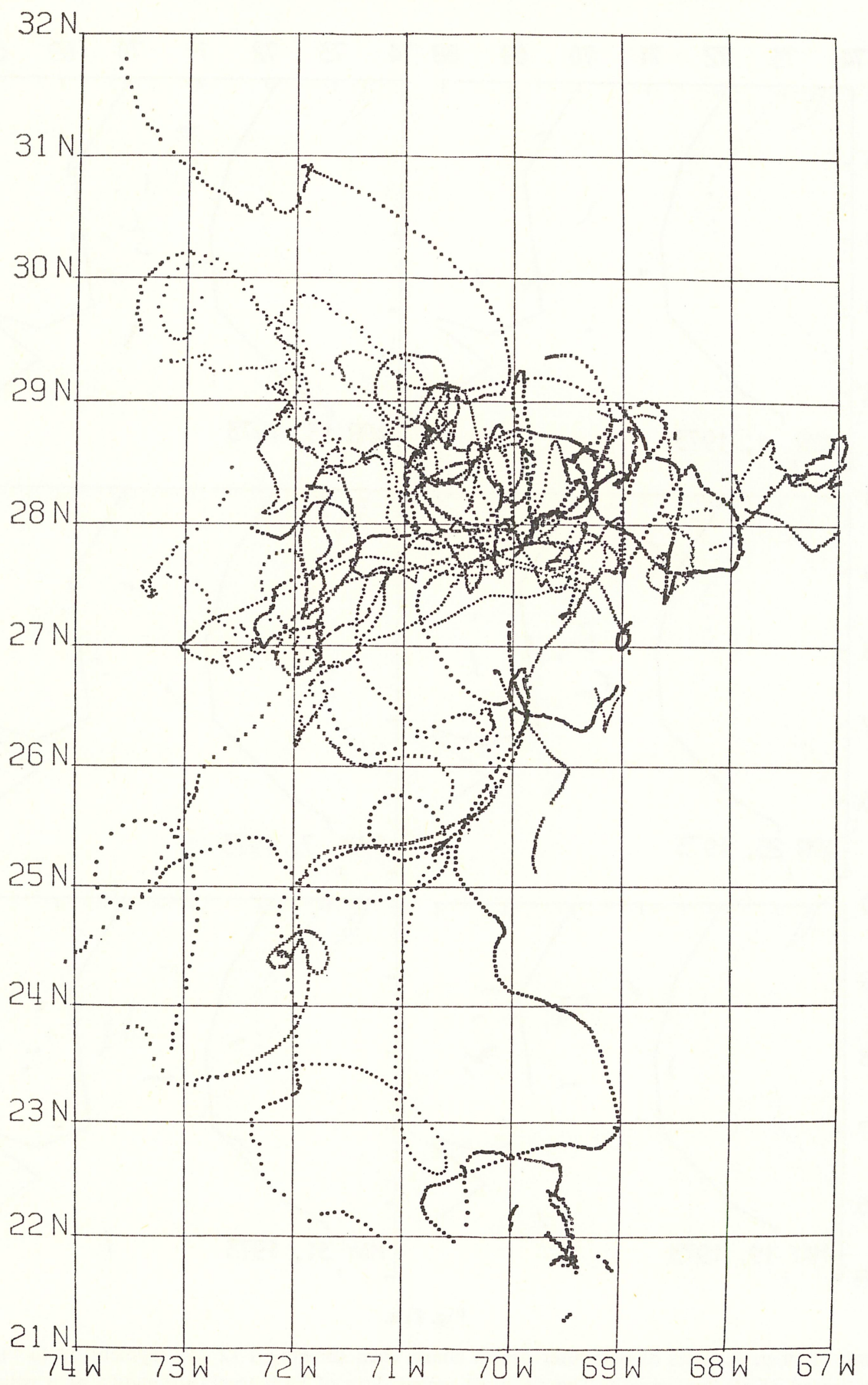

Figure 10. Spaghetti diagram in which all float trajectories between 9/28/72 and 12/31/74 are superimposed. The dots along the tracks are $1 /$ day. Note the non-randon orientation of float paths. 

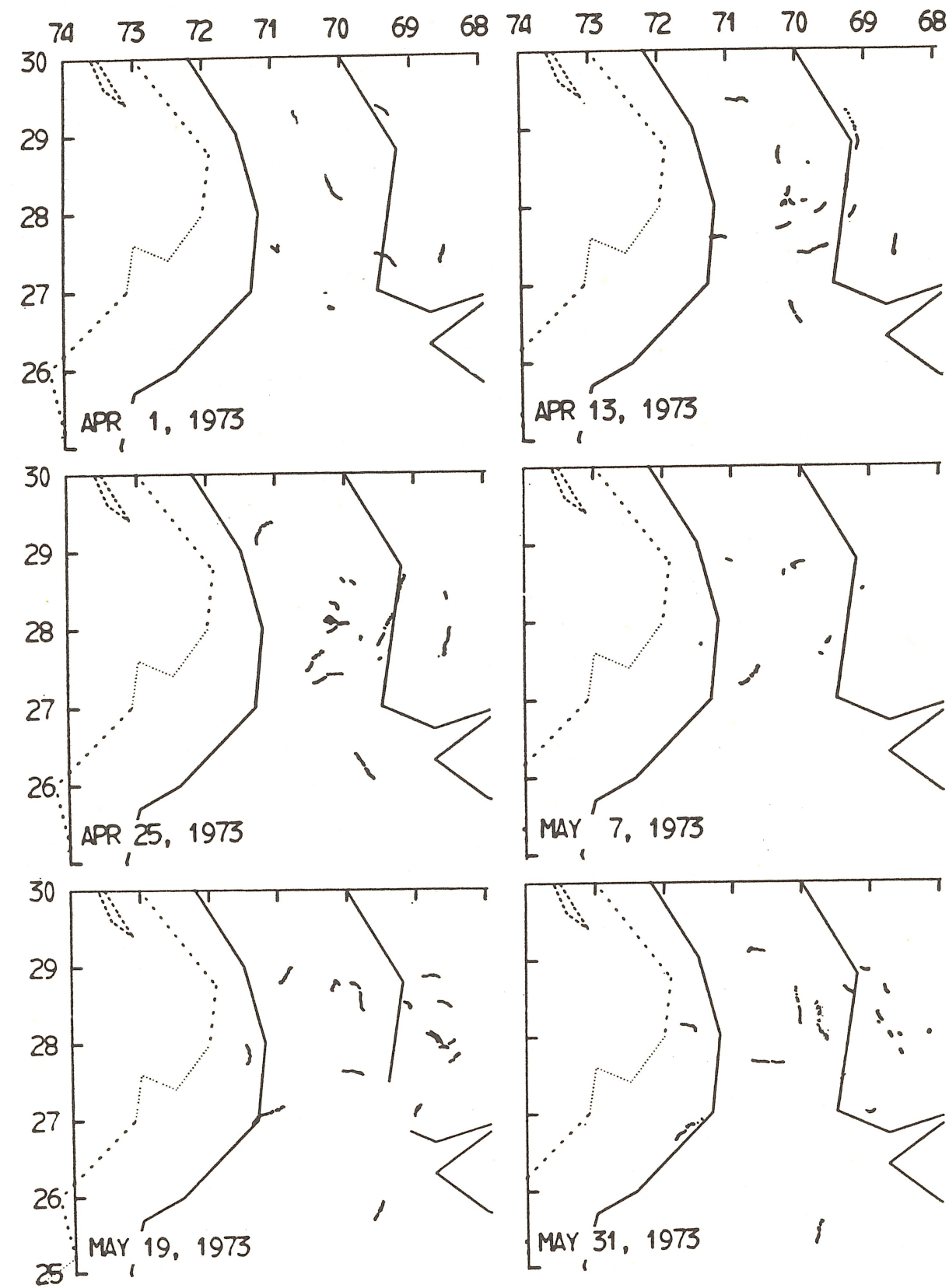

Fig. 11 a.

Figure 11. a-g. A series of computer drawn charts each showing a 12 day segment up to the day indicated of all float tracks. The six most recent days of each track are shown as a solid line and the six prior days are dashed. The bold solid and dashed line represent the 5400 meter and 

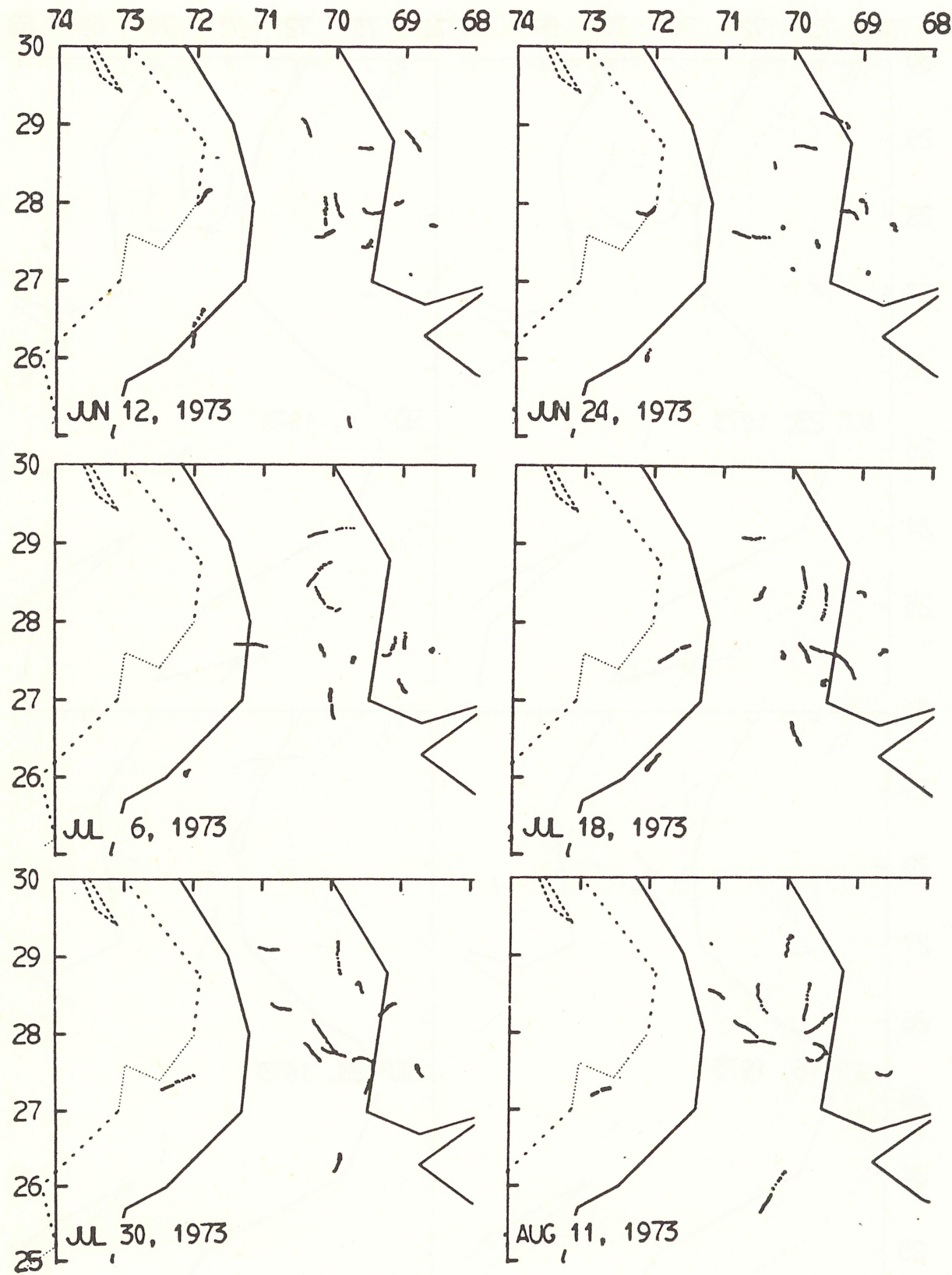

Fig. $11 \mathrm{~b}$.

5000 meter isobaths respectively. In the northwestern corner the 4000 meter contour on the Blake-Bahama Ridge is indicated. 


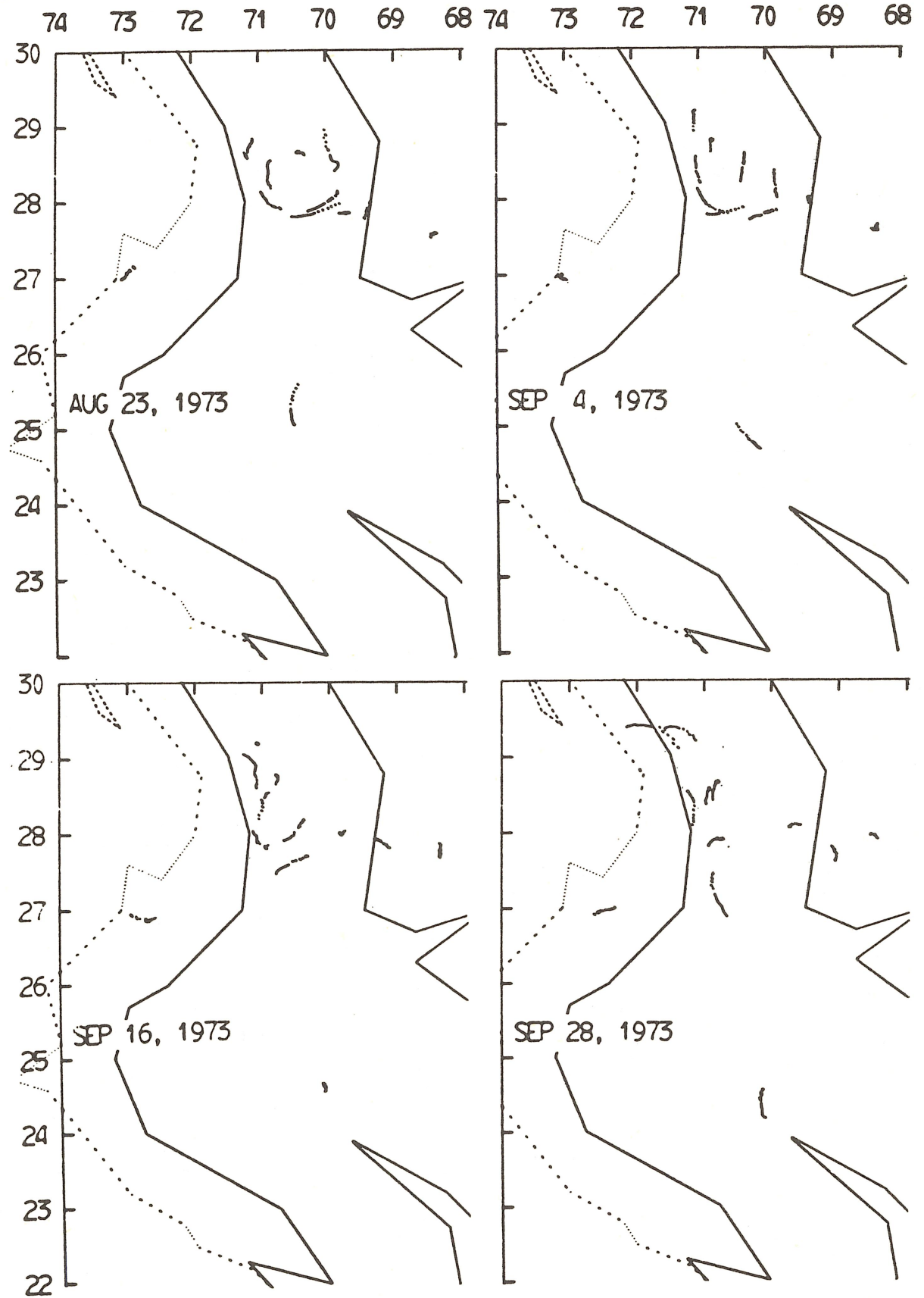

Fig. 11c. 


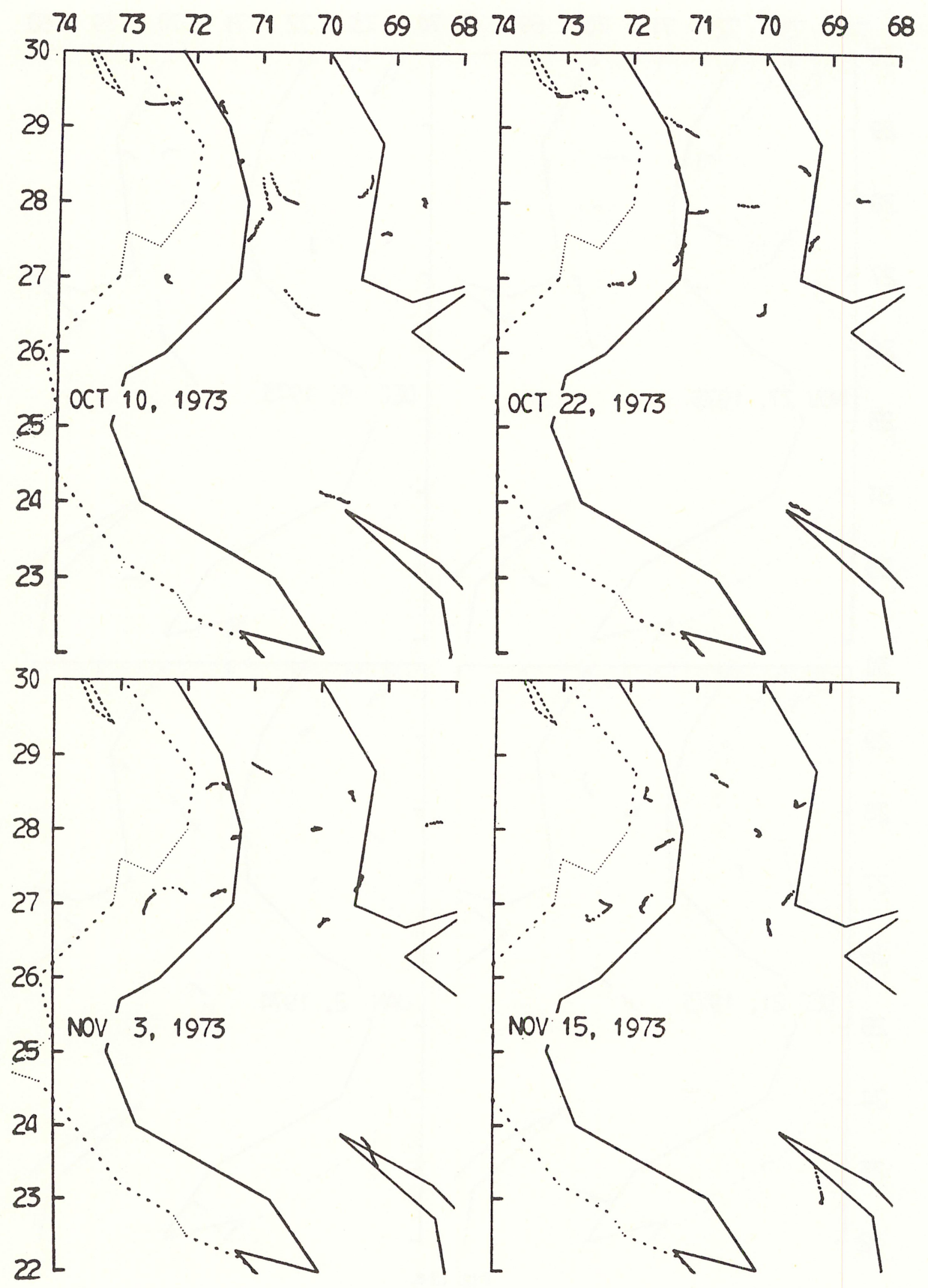

Fig. $11 \mathrm{~d}$. 

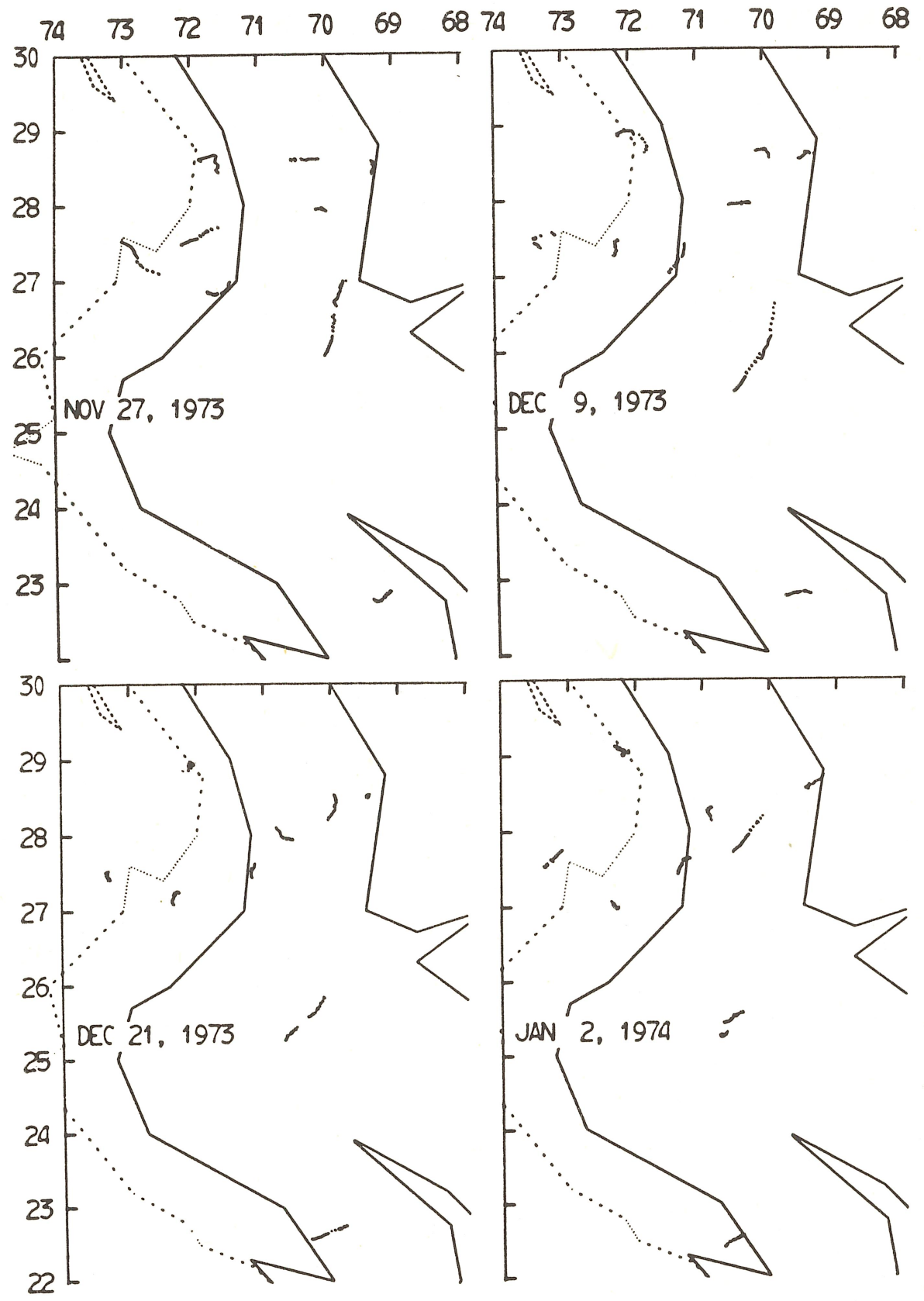

Fig. $11 \mathrm{e}$. 


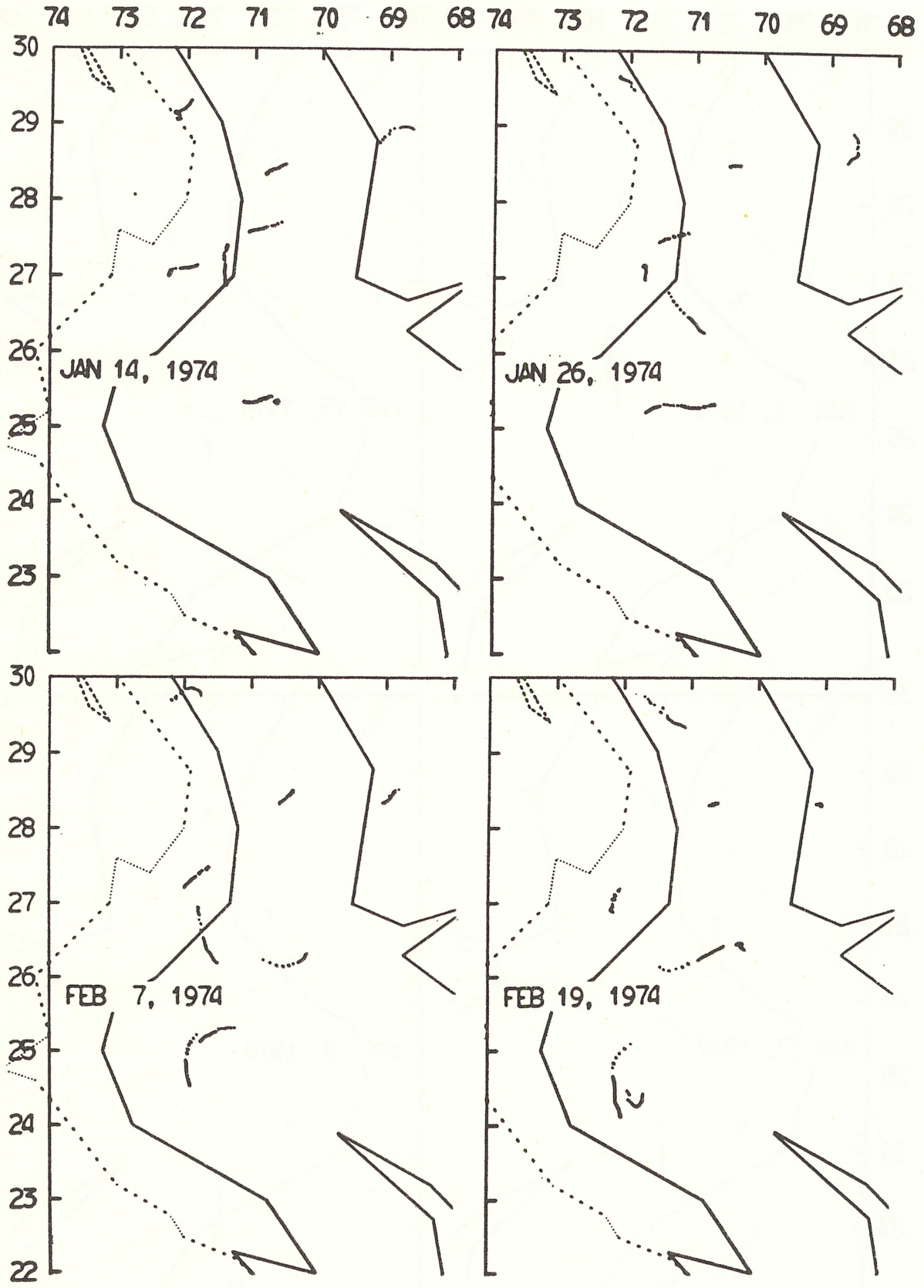

Fig. $11 \mathrm{f}$. 


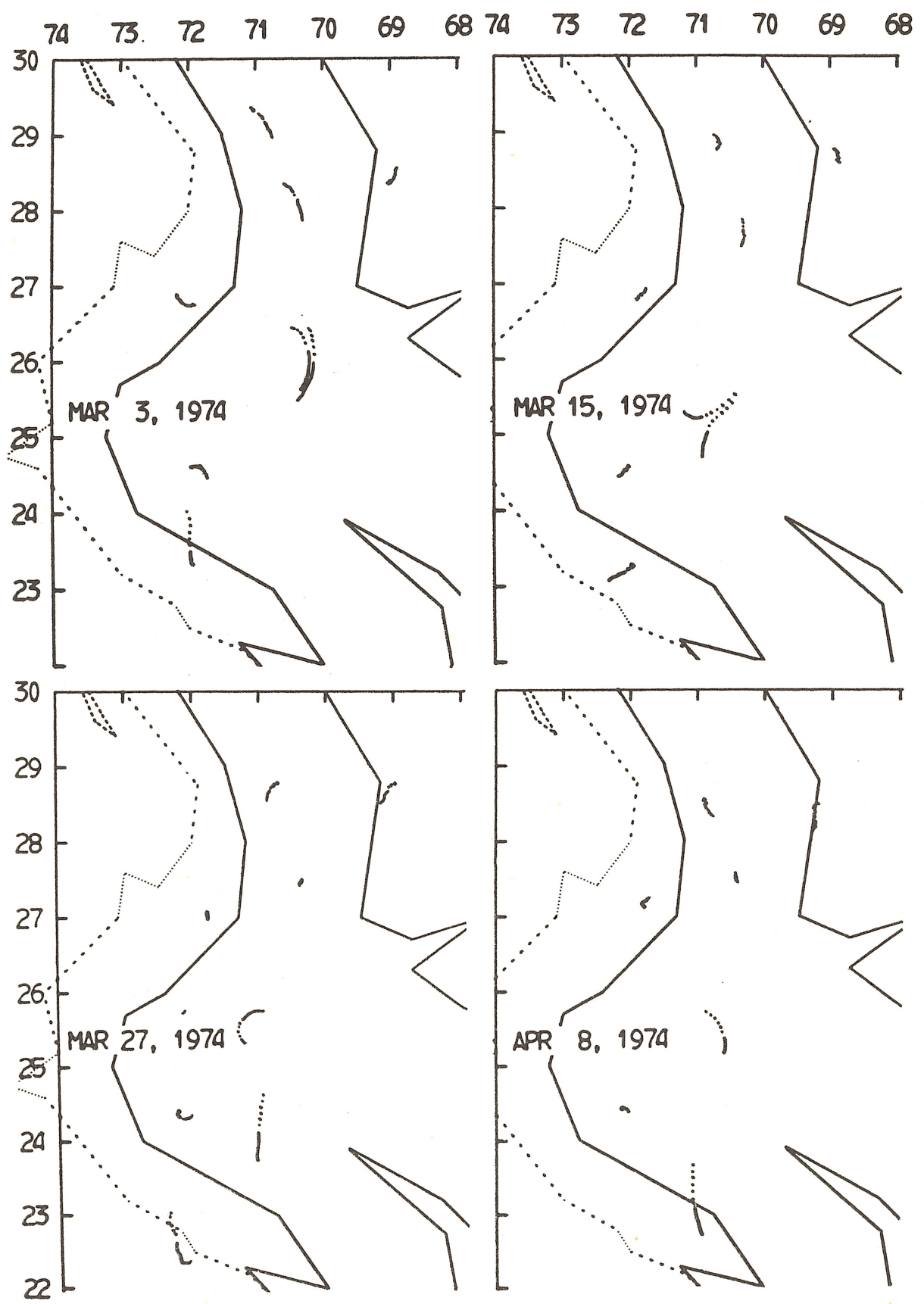

Fig. $11 \mathrm{~g}$. 

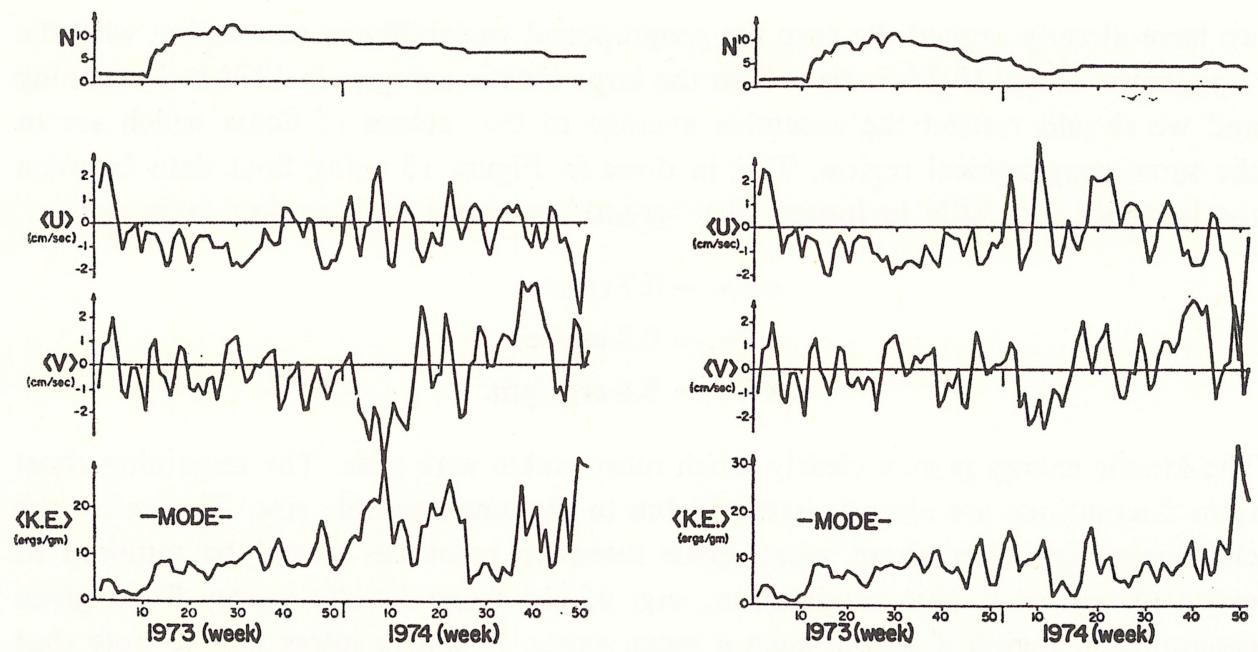

Figure 12. Cluster average over all floats of velocity and kinetic energy as a function of time. Also shown are the number of floats

Figure 13. Cluster average over all floats between $26^{\circ}-30^{\circ} \mathrm{N}$ inclusive of velocity and kinetic energy as a function of time.

e. Temporal variations of the cluster average. The data set obtained with the floats at present spans almost two years. The number of instruments at any given time ranges from a high of 14 to 5 in May 1975. Each of these is moving about in a pattern governed by the fluctuating meso-scale eddy field and by the mean field, which may or may not be coherent over larger horizontal scales. By taking averages over the entire cluster of $u, v$ and kinetic energy, $K E=1 / 2\left(u^{2}+v^{2}\right)$ over all time one obtains "grand" averages for this data set. By taking a cluster average locally in time, say weekly, one can look at their temporal variability. This can be of significant value in deciding whether or not the grand average is stable.

In Figure 12 we have plotted as a function of time the number, $N$, of floats being tracked, $\langle u(t)\rangle,\langle v(t)\rangle,\langle K E\rangle$ where $\langle>$ is the average over all float days for a given week. The grand averages over all data for

$$
\begin{array}{ll}
u, v, E \quad \text { are } \quad & <\bar{u}>=-0.6 \mathrm{~cm} / \mathrm{sec} \\
& <\bar{v}>=-0.3 \mathrm{~cm} / \mathrm{sec} \\
& <K E>=11.4 \mathrm{ergs} / \mathrm{gm} .
\end{array}
$$

It is evident that if the 1973 section were divided into two parts, about the same values for $\langle\bar{u}\rangle$ and $\langle\bar{v}\rangle$ could obtain for each subset. In February 1974, however, a rapid movement of four floats to the south strongly magnify $\langle v\rangle$ and $\langle K E\rangle$. By this time the floats are rather widely dispersed and we are consequently confronted with the possibility that cluster or ensemble averaging may no longer be valid if the floats are spread over geographical regions that are energetically dissimilar. Indeed, 
we have already argued the case for geographical variability in connection with the "spaghetti" chart. If this is true, then the large kinetic energies in 1974 lack meaning and we should restrict the ensemble average to that subset of floats which are in the same geographical region. This in done in Figure 13 using float data between the latitudes $26^{\circ}-30^{\circ} \mathrm{N}$ inclusive. The "grand" averages for this data base are

$$
\begin{aligned}
<\bar{u}> & -0.7 \mathrm{~cm} / \mathrm{sec} \\
<\bar{v}> & =0.2 \mathrm{~cm} / \mathrm{sec} \\
<K E> & =8.6 \mathrm{rgs} / \mathrm{gm} .
\end{aligned}
$$

The kinetic energy is now clearly much more stable with time. The remaining short term fluctuations are almost certainly due to the small sample size. This raises the challenging question about what space intensive resources would be required in order to resolve a $20 \%$ modulation, say, of the mean kinetic energy for a given geographical region if indeed such a mean exists. It is also interesting to note that $<u(t)>$ is more stable in 1973 than in 1974. This is partly due to the decreasing number of instruments with time. It is reasonable that even though the 1974 data base for $\langle u(t)>$ and $\langle v(t)>$ spans five float years we must conclude from Figure 13 that it is insufficient to determine the mean field with any degree of confidence. This suggests to us that meaningful averages will be very difficult to obtain by time averaging alone.

The corresponding "grand" averages for all float data (= 1595 float days) south of $26^{\circ} \mathrm{N}$ are:

$$
\begin{aligned}
<\bar{u}> & =-0.3 \mathrm{~cm} / \mathrm{sec} \\
<\bar{v}> & =-1.6 \mathrm{~cm} / \mathrm{sec} \\
<K E> & =19 \mathrm{ergs} / \mathrm{gm} .
\end{aligned}
$$

Due to the smaller sample size these numbers are rather noisy. There is no question, however, that the kinetic energy levels are at least a factor of 2 higher. This is evident from the spaghetti diagram and emphasizes the fact that there exist strong local variations in the kinetic energy levels. This suggests that we should pay closer attention to the frequently made assumption that the scale of variation of the (second order) eddy statistics is large compared to the eddies themselves.

\section{Preliminary results from float sensors}

a. Internal wave field. All instrumented floats showed that a great deal of the variability in water temperature and vertical motion was caused by internal waves which advect water with its thermal microstructure up and down past the float as it drifts. This is illustrated in (the upper half of) Figure 14 which shows that frequency spectrum of the variance of vertical water velocity (twice the vertical kinetic energy) computed from a 36-day drift record. The vertical velocity was calculated from the relative flow past the float corrected for the slight bobbing motion of the float itself 

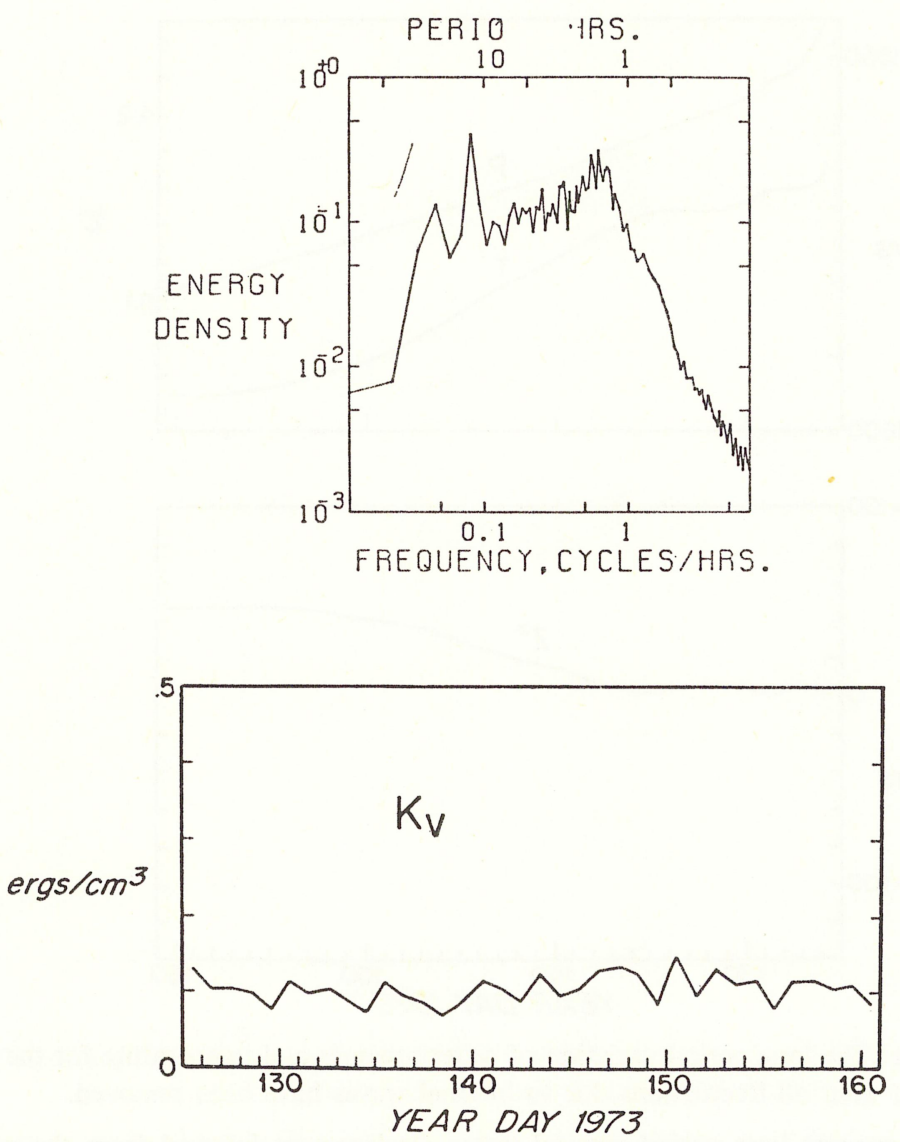

Figure 14. Upper: Mean power spectrum of vertical water velocity at a SOFAR float averaged over a drift of 36 days at a depth of $1560 \mathrm{~m}$. The units of energy density are $(\mathrm{cm} / \mathrm{sec})^{2} /(\mathrm{cycle} / \mathrm{hr})$.

Lower: The daily variation of vertical water kinetic energy at the same float.

using the pressure data. Most of the energy is distributed rather uniformly between two periods; the mean local inertial period of 26.4 hours, and the mean Väisälä period of 1.24 hours appropriate to the density stratification at the float depth $(1560 \mathrm{~m})$. The spectrum of the total kinetic energy of the internal wave field is, of course, quite different since the inertial oscillations are predominantly horizontal. The spectrum also exhibits a significant energy peak at the $M_{2}$ tide (12.42 hours). All floats over the 4-month period of MODE, drifting in an area $300 \mathrm{~km}$ square, gave spectra remarkably similar in shape and magnitude to that shown.

The daily variation of the total vertical kinetic energy of the water at the above float as it drifted is shown by the curve in the lower half of Figure 14. Because over $95 \%$ of this energy is due to motions with period shorter than one day, such a plot is a rather good representation of the internal wave sea state. It appears remarkably 

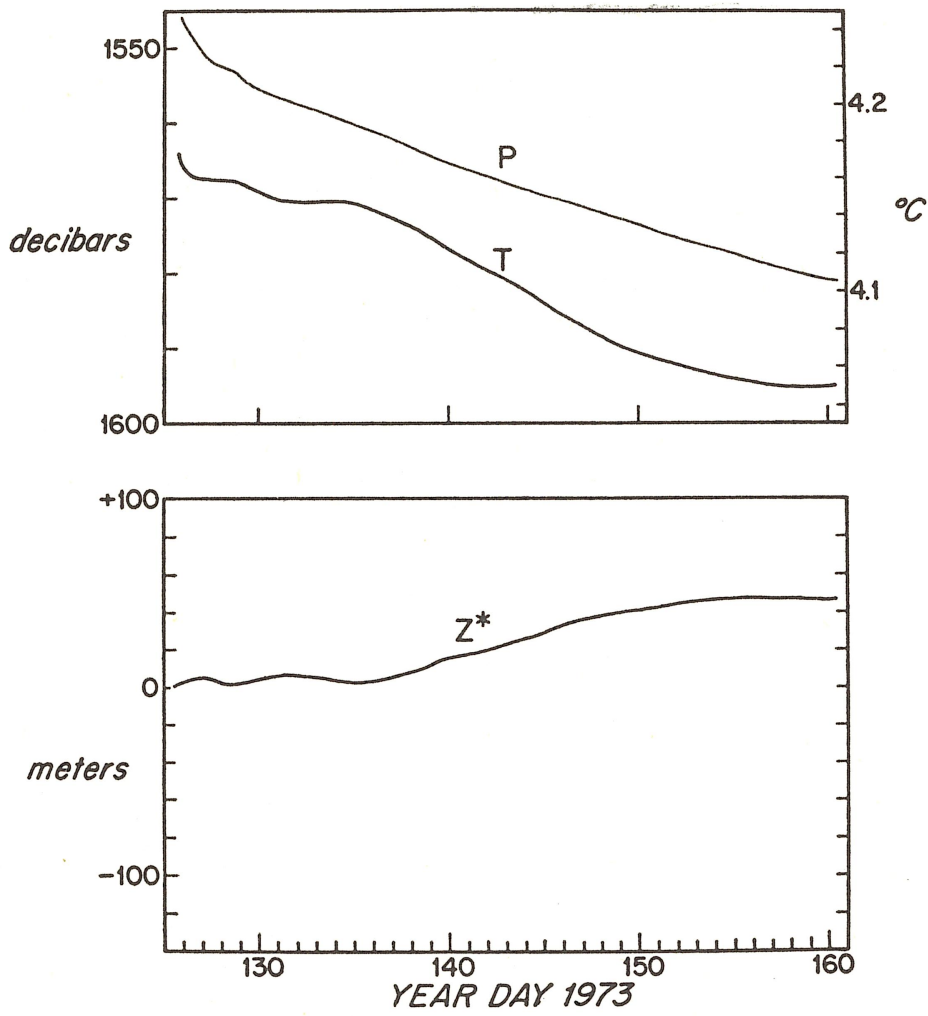

Figure 15. Upper: The long period variation of water pressure and temperature for the same float as in Fig. 5.1.1 after all fluctuations due to internal waves have been removed.

Lower: The apparent long period vertical water displacement inferred from the variation of temperature and pressure shown in the upper panel assuming a vertical temperature gradient of $1.5 \mathrm{mil} \mathrm{deg} / \mathrm{m}$.

steady over the drift period with variations of no more than $30 \%$. The daily r.m.s. internal wave vertical velocity and amplitude were, on average, $0.40 \mathrm{~cm} / \mathrm{sec}$ and $10.0 \mathrm{~m}$ respectively.

b. Low frequency vertical motions. Of special interest to MODE were the long period changes in the float's environment after the effects of internal waves were removed. Shown in the upper part of Figure 15 are the water pressure and temperature, at the float discussed above, after all fluctuations shorter than 2 days were filtered from the record. As mentioned before, the steady pressure increase indicates a slow sinking of the float due to compressional creep of the main cylinder. The water temperature also decreases as the float sinks but at a rate greater than that which can be accounted for by the mean vertical temperature gradient, implying a net upward displacement of the water during the drift. This displacement had been 
computed from the temperature and pressure change, assuming a mean gradient of $.0015^{\circ} \mathrm{C} / \mathrm{m}$, and is shown in the lower part of Figure 15. The apparent upward displacement of approximately $50 \mathrm{~m}$ of water in 35 days is consistent with similar temperature changes observed from numerous CTD stations made during MODE and is caused (probably) by slow geostrophic adjustments of the density field.

Unfortunately, our direct measurements of vertical water displacements, after we have filtered out the high frequency components, do not compare well with the slow displacements inferred from temperature changes. A very likely cause of this is the basic vertical asymmetry of the SOFAR float (Figure 2) which was dictated at the time by the acoustic engineering. Our calibration of float rotation as a function of up and down flow was simply not precise and sophisticated enough to prevent the real long period displacements from being masked by rectified internal wave motions. The data is still being studied for other sources of error.

Acknowledgements. This program would not have been possible without the generous support and assistance of many individuals. The stimulus for the early development of the SOFAR float program as well as for our participation in MODE comes from Professor H. Stommel. We are deeply grateful to him for his continuing encouragement throughout all phases of this program. For several years the development of and research with SOFAR floats was supported by the Office of Naval Research under contracts NO0014-66-C-0241 to the Woods Hole Oceanographic Institution and N00014-67-A-0097-001 to Yale University. Out participation in MODE-I was made possible by support from the International Decade of Ocean Exploration program of the National Science Foundation (GX 30220 to WHOI, GX 30416 to Yale University) and the Office of Naval Research. Without this support a space-intensive experiment of this magnitude would simply not have been possible.

Many individuals have extended critical support. The contributions by Mr. Raymond Benoit, Mr. Donald Dorson and Mr. Kenneth Fairhurst to the development and preparation of 20 floats for MODE are gratefully acknowledged. Mr. Elliot Kulbersh at Yale University did an excellent job on the development and installation of the receiver instrumentation at the shore stations. During the main phase of MODE-I the stations were also supported by Mr. Lawrence Connell, Mr. David Dorson, and Mr. Wilson Lamb. Mr. Chauncey Dunn has extended valuable support throughout the entire program. Ms. Diane Dow has provided excellent programming support for several years. This includes the trajectory figures in this paper. She and Ms. Kathy Keleher have been responsible for the data reduction and the float trajectory computations. This is no trivial job when a float clock goes wrong or when the signals get faint! To all of you we extend our sincere thanks. We are very grateful to the master and crew of the NOAA ship RESEARCHER who were most helpful during all phases of the work at sea.

\section{REFERENCES}

Crease, J. 1962. Velocity measurements in the deep water of the western North Atlantic. J.Geophys. Res., 67: 3173-3176.

Freeland, H. J., P. B. Rhines, and T. Rossby. 1975. Statistical observations of the trajectories of neutrally buoyant floats in the North Atlantic. J. Mar. Res., 33: 383-404.

Phillips, N. 1966. Large-scale eddy motion in the western Atlantic. J. Geophys. Res., 71: 3883-3891.

Rossby, T. and D. Webb. 1970. Observing abyssal motions by tracking Swallow floats in the SOFAR Channel. Deep-Sea Res., 15: 359-365. 
Rossby, T. and D. Webb. 1971. The four month drift of a Swallow float. Deep-Sea Res., 18: 10351039.

Voorhis, A. D. 1968. Measurements of vertical motion and the partition of energy in the New England slope water. Deep-Sea Res., 15: 599-608.

Voorhis, A. D. and D. C. Webb. 1973. Data summary and review of shipboard SOFAR float program from September 1972 through July 1973. W.H.O.I. Tech. Rpt. 73-74.

Voorhis, A. D. and R. R. Benoit. 1974. MODE SOFAR float in situ data summary. W.H.O.I. Tech. Rep. 74-37.

Walden, R. G., H. O. Berteaux and F. Striffer. The design logistics and installation of a SOFAR float tracking station at Grand Turk Island, B.W.I. W.H.O.I. Tech. Rpt. 73-73.

Webb, D. C. and L. V. Worthington. 1968. Measurements of vertical water movement in the Cayman Basin. Deep-Sea Res., 15: 609-612.

Woods Hole Oceanographic Institution Contribution Number: 3055. MODE Contribution Number: 47.

Received: 19 March, 1975; revised: 26 June, 1975.

\author{
Printed in Denmark for the Sears Foundation for Marine Research, \\ Yale University, New Haven, Connecticut 06520, U.S.A. \\ Bianco Lunos Bogtrykkeri A/S, Copenhagen, Denmark
}


FOR UNCLASSIFIED TECHNICAL REPORTS, REPRINTS, \& FINAL REPORTS PUBLISHED BY OCEANOGRAPHIC CONTRACTORS

OF THE OCEAN SCIENCE AND TECHNOLOGY DIVISION

OF THE OFFICE OF NAVAL RESEARCH

(REVISED OCT . 1975)

1

Director of Defense Research and Fingineering

Office of the Secretary of Defense Washington, DC 20301

ATTN: Office Assistant Director (Research)

Office of Naval Research

Arlington, VA 22217

3 ATTN: (Code 480)

1 ATTN: (Code 460)

1 ATTN: (Code 102-OS)

6 ATTN: (Code 102IP)

1 ATTN: (Code 200)

1 LCDR David Cacchione, (USN)

ONR Representative

Woods Hole Oceanographic Inst.

Woods Hole, MA 02543

1 Office of Naval Research

Branch office

495 Summer Street

Boston, MA 02210

Director

Naval Research Laboratory

Washington, DC 20375

6 ATTN: Library, Code 2620

1 National Oceanographic Data Center

National Oceanic \& Atmospheric

$\Lambda d m i n i s t r a t i o n$

Rockville, MD 20852
12 Defense Documentation Center

Cameron Station

Alexandria, VA 22314

Commander

Naval Oceanographic Office

Washington, DC 20390

1 ATTN: Code 1640

1 ATTN: Code 70 



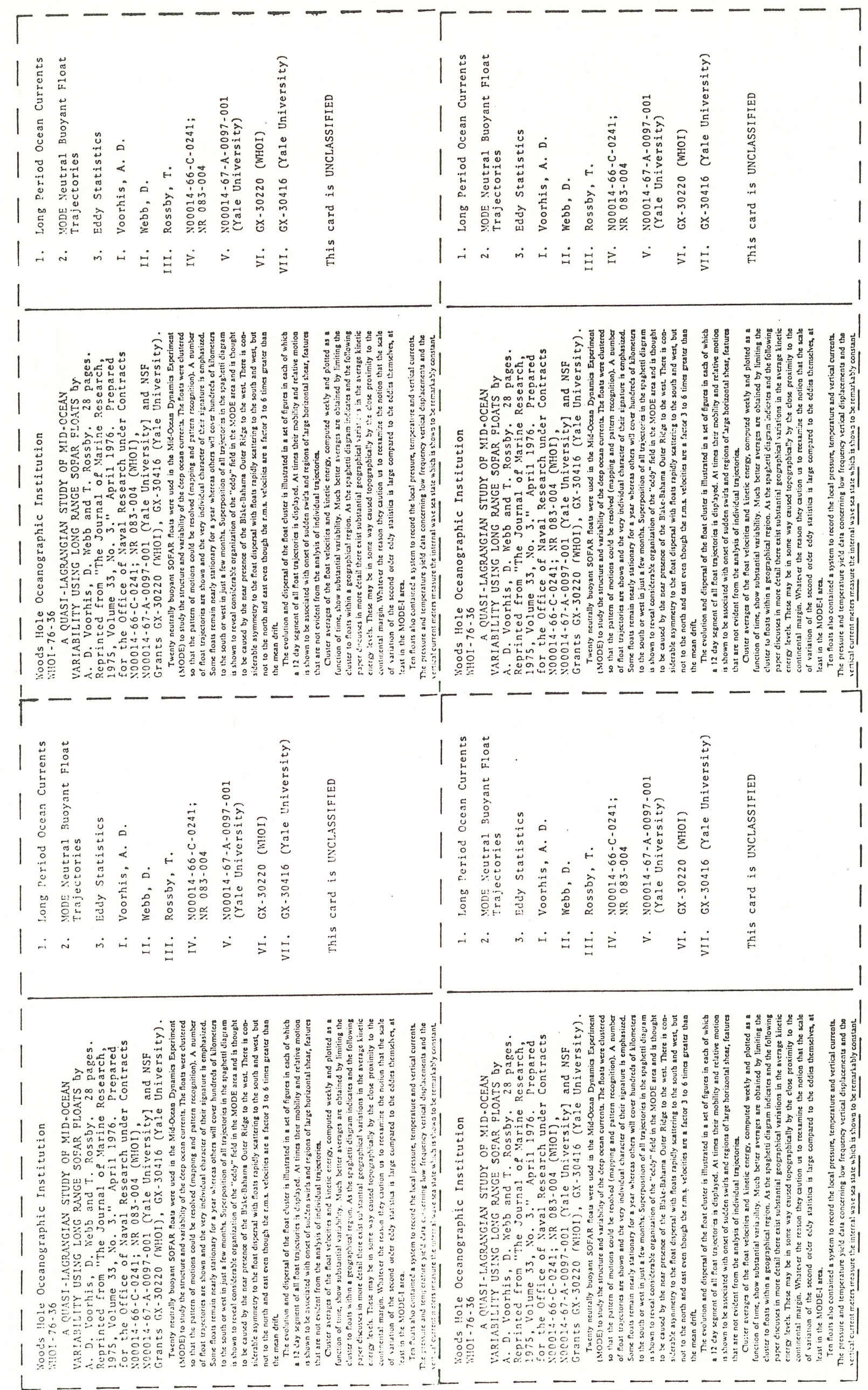





\begin{tabular}{|c|c|}
\hline REPORT DOCUMENTATION PAGE & $\begin{array}{l}\text { READ INSTRUCTIONS } \\
\text { BEFORE COMPLETING FORM }\end{array}$ \\
\hline $\begin{array}{l}\text { 1. REPORT NUMBER } \\
\text { WHOI - } 76-36 \\
\end{array}$ & 3. RECIPIENT'S CATALOG NUMBER \\
\hline \multirow{2}{*}{$\begin{array}{l}\text { 4. TITLE (and Subtitle) } \\
\text { A QUASI - LAGRANGIAN STUDY OF MID-OCEAN } \\
\text { VARIABILITY USING LONG RANGE SOFAR } \\
\text { FLOATS }\end{array}$} & $\begin{array}{l}\text { 5. TYPE OF REPORT \& PERIOD COVERED } \\
\text { TECHN ICAL }\end{array}$ \\
\hline & $\begin{array}{l}\text { 6. PERFORMING ORG. REPORT NUMBER } \\
\text { WHOI CON. NO. } 3055\end{array}$ \\
\hline $\begin{array}{l}\text { 7. AUTHOR(s) } \\
\text { A. D. Voorhis, D. Webb and T. Rossby }\end{array}$ & $\begin{array}{l}\text { 8. CONTRACT OR GRANT NUMBER(s) } \\
\text { NO0014-66-C-0241; } \\
\text { N00014-67-A-0097-001; } \\
\text { GX-30220, GX-30416 }\end{array}$ \\
\hline $\begin{array}{l}\text { 9. PERFORMING ORGANIZATION NAME AND ADDRESS } \\
\text { Woods Hole Oceanographic Institution } \\
\text { Woods Hole, Massachusetts } 02543\end{array}$ & $\begin{array}{l}\text { 10. PROGRAM ELEMENT, PROJECT, TASK } \\
\text { AREA \& WORK UNIT NUMBERS } \\
\text { NR } 083-004\end{array}$ \\
\hline \multirow{2}{*}{$\begin{array}{l}\text { 11. CONTROLLING OFFICE NAME AND ADDRESS } \\
\text { Office of Naval Research } \\
\text { Code } 480\end{array}$} & $\begin{array}{l}\text { 12. REPORT DATE } \\
\text { April } 1976 \\
\end{array}$ \\
\hline & $\begin{array}{l}\text { 13. NUMBER OF PAGES } \\
28\end{array}$ \\
\hline \multirow[t]{2}{*}{ 14. MONITORING AGENCY NAME \& ADDRESS(if difforont from Controlling Offico) } & $\begin{array}{l}\text { 15. SECURITY CLASS. (of this roport) } \\
\text { UNCLASS I FIED }\end{array}$ \\
\hline & $\begin{array}{l}\text { 15. DECLASSIFICATION/DOWNGRADING } \\
\text { SCHEDULE }\end{array}$ \\
\hline
\end{tabular}

Approved for public release; distribution unlimited.

17. DISTRIBUTION STATEMENT (of the abstract ontered in Block 20, if difforent from Report)

18. SUPPLEMENTARY NOTES

Reprinted from "The Journal of Marine Research, 1975, Volume 33, No. 3."

19. KEY WORDS (Continue on reverse side if nocessary and identify by block number)

1. Long Period Ocean Currents

2. MODE Neutral Buoyant Float Trajectories

3. Eddy Statistics

20. ABSTRACT (Continue on reverse atde if noceseary and identify by block number)

Twenty neutrally buoyant SOFAR floats were used in the Mid-Ocean Dynamics Experiment (MODE) to study the structure and variability of the deep ocean currents. The floats were clustered so that the pattern of motions could be resolved (mapping and pattern recognition). A number of float trajectories are shown and the very individual character of their signature is emphasized. Some floats remain nearly stationary for a year whereas others will cover hundreds of kilometers to the south or west in just a few months. Superposition of all trajectories in the spaghetti diagram is shown to reveal considerable organization of the "eddy" field in the MODE area and is thought to be caused by the near presence of the Blake-Bahama Outer Ridge to the west. There is con-

(Cont.on Back) 
siderable asymmetry to the float dispersal with floats rapidly scattering to the south and west, but not to the north and east even though the r.m.s. velocities are a factor 3 to 6 times greater than the mean drift.

The evolution and dispersal of the float cluster is illustrated in a set of figures in each of which a 12 day segment of all float trajectories is displayed. At times their mobility and relative motion is shown to be associated with onset of sudden swirls and regions of large horizontal shear, features that are not evident from the analysis of individual trajectories.

Cluster averages of the float velocities and kinetic energy, computed weekly and plotted as a function of time, show substantial variability. Much better averages are obtained by limiting the cluster to floats within a geographical region. As the spaghetti diagram indicates and the following paper discusses in more detail there exist substantial geographical variations in the average kinetic energy levels. These may be in some way caused topographically by the close proximity to the continental margin. Whatever the reason they caution us to reexamine the notion that the scale of variation of the second order eddy statistics is large compared to the eddies themselves, at least in the MODE-I area.

Ten floats also contained a system to record the local pressure, temperature and vertical currents. The pressure and temperature yield data concerning low frequency vertical displacements and the vertical current meters measure the internal wave sea state which is shown to be remarkably constant. 